\title{
Strength curves for web crippling design of cold-formed stainless steel
}

\section{hat sections}

\author{
M. Bock, E. Real \\ ${ }^{a}$ Department of Construction Engineering, Universitat Politècnica de Catalunya, UPC \\ C/ Jordi Girona, 1-3. 08034 Barcelona, Spain \\ * Corresponding author: Tel: +0034 934054156, Fax: +0034 934054135, e-mail: \\ marina.bock@upc.edu
}

\begin{abstract}
The web crippling design guides are based on empirical adjustments of available test data. These equations differ from the basic concept underpinning most of the other instabilities, the so-called strength curves. This investigation presents a new design approach for web crippling design of stainless steel hat sections based on strength curves controlled by slenderness-based functions $\chi(\bar{\lambda})$. The effects of web crippling on such cross-sections were studied numerically and the obtained results were used to derive the design expressions. Comparisons with tests and FE data, and with design guides show that the proposed design approach provides more accurate web crippling resistance.
\end{abstract}

\section{Highlights}

- Literature review, including web crippling research and design

- FE simulation of stainless steel hat sections subjected to web crippling

- Development of design expressions for the proposed design approach

- Statistical validation of the proposed design method

- Comparison of the proposed method with design standards

Keywords: hat sections, reduction factor, stainless steel, strength curves, transverse forces, web crippling 


\section{Introduction}

The use of stainless steel in construction has been permanently increasing during the last years due to its favourable characteristics in terms of strength, durability, formability and aesthetics. Cold-formed stainless steel hat sections are frequently used as secondary structural elements in roof or wall cladding subjected to local transverse loads or reactions which produce local high stresses. These cross-sections present high web-to-thickness ratio, and its web is therefore susceptible to local buckling (localized crushing or crippling of the web).

The first web crippling experimental investigation was conducted at Cornell University $[1,2]$ on cold-formed carbon steel I-sections. Within this investigation, two types of load locations and two types of loading were examined, resulting in the four types of loading cases: interior one-flange (IOF), interior two-flanges (ITF), exterior one-flange (EOF) and exterior two-flanges (ETF). Exterior loading defines a situation when the load is applied at the end of the member whereas in the case of interior loading, the load is applied within the span. Distinction is made between one flange loading or two flange loading if the load is applied through one flange or acting on both flanges, respectively. This classification was adopted in the early versions of the AISI specification [3] for cold-formed carbon steel and later on, in the first version [4] of the current SEI/ASCE 8-02 standard [5] for application to stainless steel. The European design guidance for stainless steel, EN 1993-1-4 [6], refers to the European design guidance for cold-formed carbon steel, EN 1993-1-3 [7], to predict web crippling strength where different empirical equations are given. In this latter, for the particular case of hat sections, two categories are codified: Category 1 which corresponds to EOF, ETF and ITF loading; and Category 2 which is equivalent to IOF loading.

The theoretical treatment of web crippling is rather complex because many parameters are involved [8]: cross-section geometry (I-sections, C-sections, Z-sections, hat sections and multi web sections); inclination of the web element; inside bending radius; relative slenderness of the web; the length over which the load is distributed (bearing length); loading case; steel properties; and support conditions. Consequently, current standards $[5,7]$ provide various empiric design equations for a given load case and particular cross-section geometry which were derived from regression analysis of existing test on different cold-formed carbon steel sections. Despite accurate plastic mechanism models based on yield line theory were derived for cold-formed carbon steel hat sections [9, 10], their application is rather tedious for hand calculation purposes. Relevant research regarding these adjustments is summarized in Table 1 for cold-formed carbon steel.

The applicability of the aforementioned empiric equations to stainless steel was found to be not always acceptable [11] and further research was conducted in order to adapt these equations to different stainless steel grades and cross-section types [12-16]. Other relevant studies on cold-formed stainless steels are summarized in Table 2. Indeed, these adjustments correlate well with the data they allow for but such empiric design approach deviates from the treatment of most of the other instabilities in the European structural design standards, the so-called strength curves controlled by slendernessbased functions $\chi(\bar{\lambda})$. 
Table 1. Relevant research on cold-formed carbon steel members subjected to web crippling

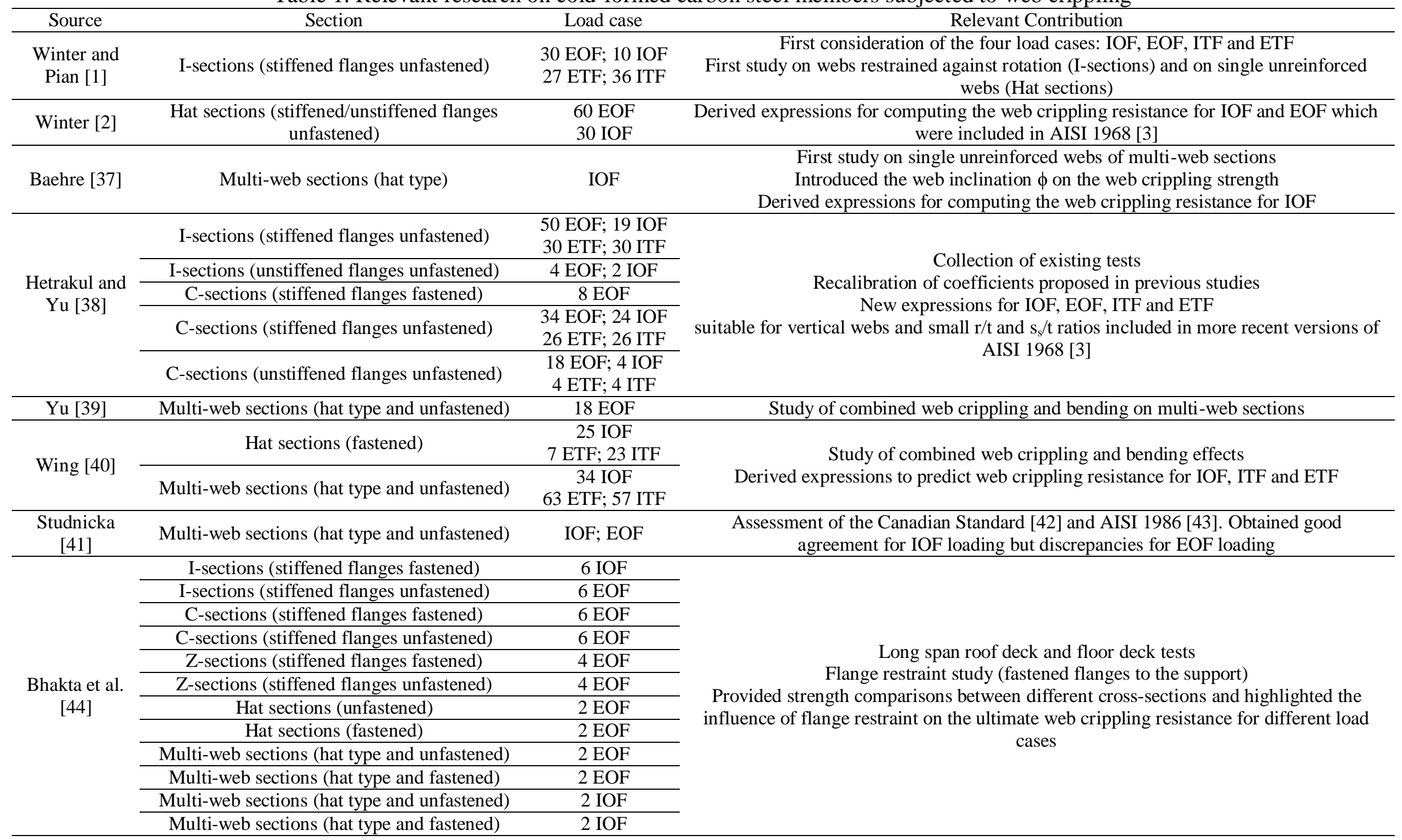




\begin{tabular}{|c|c|c|c|}
\hline Source & Section & Load case & Relevant Contribution \\
\hline $\begin{array}{l}\text { Prabhakaran } \\
\text { [45] }\end{array}$ & - & - & $\begin{array}{l}\text { Collection of all existing tests. A unified expression for web crippling design is derived } \\
\text { which was adopted in the Canadian Standard [46] and in the North American } \\
\text { Specification (NAS) [47] }\end{array}$ \\
\hline $\begin{array}{l}\text { Langan et al. } \\
{[48]}\end{array}$ & C-sections (stiffened flanges unfastened) & 23 EOF; 8 IOF & Assessment of available specifications and design recommendations \\
\hline \multirow{3}{*}{$\begin{array}{l}\text { Cain et al. } \\
\quad[49]\end{array}$} & I-sections (stiffened flanges fastened) & $12 \mathrm{IOF}$ & \multirow{3}{*}{ Assessment of available specifications and design recommendations } \\
\hline & Z-sections (stiffened flanges fastened) & $14 \mathrm{EOF}$ & \\
\hline & Z-sections (stiffened flanges unfastened) & $14 \mathrm{EOF}$ & \\
\hline Gerges [50] & C-sections (stiffened flanges fastened) & $67 \mathrm{EOF}$ & $\begin{array}{l}\text { Studied sections with large inside bending radius-to-thickness ratio. New coefficients for } \\
\text { Prabhakaran's unified equation [45] are derived }\end{array}$ \\
\hline \multirow{2}{*}{$\begin{array}{l}\text { Wu et al. } \\
\text { [51] }\end{array}$} & Hat sections (fastened) & $3 \mathrm{EOF}$ & \multirow{2}{*}{ Assessment of available specifications and design recommendations } \\
\hline & Multi-web sections (hat type and unfastened) & $16 \mathrm{ETF} ; 16 \mathrm{ITF}$ & \\
\hline $\begin{array}{l}\text { Young and } \\
\text { Hancock [52] }\end{array}$ & C-sections (unstiffened flanges unfastened) & $\begin{array}{l}14 \mathrm{EOF} ; 16 \mathrm{IOF} \\
12 \mathrm{ETF} ; 14 \mathrm{ITF}\end{array}$ & $\begin{array}{l}\text { Compared test results against AISI } 1996[53] \text { and concluded that its codified equations } \\
\text { were too optimistic for C-sections. } \\
\text { Proposed a unified expression based on a simple plastic mechanism approach }\end{array}$ \\
\hline \multirow[b]{2}{*}{ Beshara [54] } & C-sections (stiffened flanges fastened) & 18 ETF; 18 ITF & \multirow{2}{*}{$\begin{array}{l}\text { Test collection to develop an experimental database } \\
\text { Calibration of new coefficients for computing the web crippling strength of cold-formed } \\
\text { carbon steel members. Improved coefficients of AISI } 1996 \text { [53] and Canadian Standard } \\
\text { [46] and were approved by the AISI committee in the North American Specification for } \\
\text { the Design of Cold-Formed Steel Structural Members (AISI 2002) [55] }\end{array}$} \\
\hline & Z-sections (stiffened flanges fastened) & 18 ETF; 18 ITF & \\
\hline
\end{tabular}


Table 2. Relevant research on cold-formed stainless steel members subjected to web crippling

\begin{tabular}{|c|c|c|c|c|}
\hline Source & Section & Load case & $\begin{array}{l}\text { Stainless } \\
\text { steel grade }\end{array}$ & Relevant objective \\
\hline $\begin{array}{l}\text { Korvink and } \\
\text { van den } \\
\text { Berg [56] }\end{array}$ & $\begin{array}{l}\text { Stiffened C-section } \\
\text { (fastened to the support) }\end{array}$ & $98 \mathrm{IOF}$ & $\begin{array}{l}1.4016 \\
1.4003\end{array}$ & $\begin{array}{l}\text { Asses the applicability of ANSI/ASCE 8-90 [4] to stainless steel. The standard was not } \\
\text { always appropriate }\end{array}$ \\
\hline $\begin{array}{l}\text { Korvink et } \\
\text { al. [11] }\end{array}$ & $\begin{array}{l}\text { Stiffened C-section } \\
\text { (fastened to the support) }\end{array}$ & $139 \mathrm{IOF}$ & $\begin{array}{l}1.4301 \\
1.4016 \\
1.4003\end{array}$ & Asses the Applicability of ANSI/ASCE 8-90 [4] to stainless steel \\
\hline $\begin{array}{l}\text { Talja and } \\
\text { Salmi [12] }\end{array}$ & SHS, RHS & $6 \mathrm{IOF}$ & 1.4301 & $\begin{array}{l}\text { Provide tests results on austenitic square and rectangular hollow sections (SHS ans } \\
\text { RHS, respectively) for the development of European design rules. Since EN 1993-1-3 } \\
\text { does not explicitly include coefficients for SHS and RHS, coefficients for sheeting } \\
\text { profiles are recommended }\end{array}$ \\
\hline \multirow{3}{*}{ Talja [57] } & Multi-web section unstiffened & $3 \mathrm{IOF}$ & \multirow{3}{*}{1.4301} & \multirow{3}{*}{ Assess the applicability of EN 1993-1-3 [7] to austenitic stainless steel } \\
\hline & $\begin{array}{l}\text { Multi-web section stiffened flanges } \\
\left(1^{\text {st }} \text { generation sheets }\right)\end{array}$ & $3 \mathrm{IOF}$ & & \\
\hline & $\begin{array}{l}\text { Multi-web section stiffened flanges } \\
\left.\text { and webs ( } 2^{\text {nd }} \text { generation sheets }\right)\end{array}$ & $3 \mathrm{IOF}$ & & \\
\hline Sélen [58] & I-sections & $\begin{array}{l}5 \mathrm{IOF} \\
4 \mathrm{EOF}\end{array}$ & 1.4301 & Assess the applicability of EN 1993-1-3 [7] to austenitic stainless steel \\
\hline Zilli [59] & $\begin{array}{l}\text { Trapezoidal section (Hat with } \\
\text { inclined webs) }\end{array}$ & $8 \mathrm{IOF}$ & $\begin{array}{l}1.4318 \mathrm{C} 700 \\
1.4318 \mathrm{C} 850 \\
\end{array}$ & \multirow{2}{*}{$\begin{array}{l}\text { Assess the applicability of EN 1993-1-3 [7] to high-strength austenitic stainless steel, } \\
\text { including web crippling and combined bending and web crippling. A new interaction } \\
\text { equation, which is less conservative, is recommended }\end{array}$} \\
\hline Talja [36] & \begin{tabular}{c|} 
Trapezoidal section \\
Trapezoidal section stiffened flange \\
Hat sections \\
\end{tabular} & \begin{tabular}{l|}
$3 \mathrm{IOF}$ \\
$6 \mathrm{IOF}$ \\
$6 \mathrm{IOF}$ \\
\end{tabular} & $\begin{array}{l}1.4318 \mathrm{C} 700 \\
1.4318 \mathrm{C} 850\end{array}$ & \\
\hline $\begin{array}{l}\text { Zhou and } \\
\text { Young [13] }\end{array}$ & SHS, RHS & 17 ETF; 16 ITF & 1.4301 & $\begin{array}{l}\text { Proposal of a unified web crippling equation with new coefficients for cold-formed } \\
\text { stainless steel sections with single webs }\end{array}$ \\
\hline $\begin{array}{l}\text { Zhou and } \\
\text { Young [14] }\end{array}$ & SHS, RHS & $\begin{array}{l}14 \mathrm{EOF} ; 14 \mathrm{IOF} \\
15 \mathrm{ETF} ; 15 \mathrm{ITF}\end{array}$ & $\begin{array}{l}\text { HSA, } \\
\text { Duplex }\end{array}$ & $\begin{array}{l}\text { Assessment of different design rules and adjustment of new coefficients of } \\
\text { Prabhakaran's [45] and Beshara's [54] unified formula for high-strength SHS and RHS }\end{array}$ \\
\hline $\begin{array}{l}\text { Zhou and } \\
\text { Young [15] }\end{array}$ & SHS, RHS & $\begin{array}{l}32 \mathrm{EL} \\
32 \mathrm{IL}\end{array}$ & $\begin{array}{l}1.4301 \\
\text { HSA } \\
\text { Duplex }\end{array}$ & $\begin{array}{c}\text { Floor joints simulation (section supported along its longitudinal axis). Assessment of } \\
\text { the suitability of the web crippling design rules in the current specifications for } \\
\text { stainless steel SHS and RHS under this load configuration. New coefficients are } \\
\text { adjusted }\end{array}$ \\
\hline $\begin{array}{l}\text { Zhou and } \\
\text { Young [60] }\end{array}$ & SHS, RHS & $21 \mathrm{IOF}$ & $\begin{array}{c}\text { HSA } \\
\text { Duplex }\end{array}$ & $\begin{array}{l}\text { Assessment of design rules to investigate the cold-formed stainless steel members } \\
\text { subjected to combined bending and web crippling. }\end{array}$ \\
\hline
\end{tabular}


Hence, the purpose of this paper is to develop a new design approach for web crippling design of cold-formed stainless steel hat sections under IOF loading (Category 2) and EOF loading (Category 1) employing strength curves $\chi(\bar{\lambda})$. To this end, collected tests on ferritic stainless steel hat sections [17] were modelled with ABAQUS to develop and calibrate a comprehensive finite element (FE) model. Since the amount of existing test data is quite scarce and having validated the numerical model, parametric studies were conducted to extend the available database over a large range of hat section geometries and two stainless steel grades: austenitic and ferritic. Following analysis of results, the proposed design equations are derived through semi-empiric analyses and statistically validated according to Annex D of EN 1990 [18]. Finally, the resistances achieved in the generated models and existing tests are compared with predicted resistances using different methods, including the proposed design approach, EN 1993-1-3 [7] design provisions and the North American SEI/ASCE 8-02 [5] standard. The design rules for the web crippling design of cold-formed hat sections given in those standards $[5,7]$ are also outlined in this paper.

\section{Current design equations}

\subsection{EN 1993-1-3}

As given in EN 1993-1-3 [7], the local transverse resistance per web $R_{w, R d}$ of a hat section should be determined according to Eq. (1) using the symbols illustrated in Fig. 1 where $r$ is the inside bending radius of the corners, $t$ is the thickness, $\phi$ is the relative angle between the web and the flange, $\mathrm{E}$ is the material Young's modulus, $\mathrm{f}_{\mathrm{yb}}$ is taken as the material proof strength $\sigma_{0.2}$ for stainless steel and $\gamma_{\mathrm{M} 1}$ is the partial safety factor with a recommended value of 1.1 for stainless steel as specified in EN1993-1-4 [6]. The expression also depends on the effective bearing length $1_{\mathrm{a}}$ and the non-dimensional coefficient $\alpha$ which must be taken according to the relevant loading Category and the cross-section shape. The values of these parameters for hat sections are: for Category 1 (EOF) $l_{a}=10 \mathrm{~mm}$ and $\alpha=0.057$; whereas for Category 2 (IOF) $l_{a}=s_{s}$ where $s_{s}$ is the bearing length and $\alpha=0.115$. Some geometrical limitations to satisfy are also provided in the design standard: $\mathrm{r} / \mathrm{t} \leq 10 ; \mathrm{h} / \mathrm{t} \leq 200 \sin \phi ; 45^{\circ} \leq \phi \leq 90^{\circ}$, where $\mathrm{h}$ is the web height between midlines of the flanges (see Fig. 1); and the clear distance from either the support reaction or local load to a free end must be at least $40 \mathrm{~mm}$.

$R_{w, R d}=\alpha t^{2} \sqrt{f_{y b} E}\left(1-0.1 \sqrt{\frac{r}{t}}\right)\left(0.5+\sqrt{\frac{0.02 l_{a}}{t}}\right)\left(2.4+\left(\frac{\phi}{90}\right)^{2}\right) / \gamma_{M 1}$

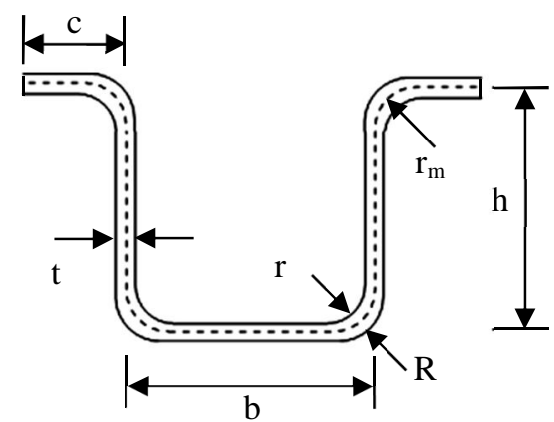

Fig. 1. Definition of symbols in the cross-section

In such circumstances where an applied local transverse force $F_{E d}$ interacts with a bending moment $\mathrm{M}_{\mathrm{Ed}}$ (eg. intermediate supports - Category 2 or equivalently IOF 
loading), $\mathrm{F}_{\mathrm{Ed}}$ should satisfy Eq. (2) where $\mathrm{M}_{\mathrm{c}, \mathrm{Rd}}$ is the moment resistance of the crosssection and $R_{w, R d}$ is the sum of the local transverse resistances of the individual webs as given by Eq. (1). Eq. (2) results into Eq. (3), when the induced bending moment $\mathrm{M}_{\mathrm{Ed}}$ by the local load $\mathrm{F}_{\mathrm{Ed}}$ is introduced according to $\mathrm{M}_{\mathrm{Ed}}=\mathrm{F}_{\mathrm{Ed}}\left(\mathrm{L}_{\mathrm{s}}-\mathrm{s}_{\mathrm{s}}\right) / 4$ where $\mathrm{L}_{\mathrm{s}}$ is the span as shown in Fig.2.

$$
\begin{array}{ccc}
\frac{F_{E d}}{R_{w, R d}}+\frac{M_{E d}}{M_{c, R d}} \leq 1.25 & \frac{F_{E d}}{R_{w, R d}} \leq 1 & \frac{M_{E d}}{M_{c, R d}} \leq 1 \\
F_{E d}=1.25 /\left(\frac{1}{R_{w, R d}}+\frac{L_{s}-s_{s}}{4 M_{c, R d}}\right) & \leq \min \left\{F_{E d}, 4 M_{c, R d} /\left(L_{s}-s_{s}\right)\right\}
\end{array}
$$

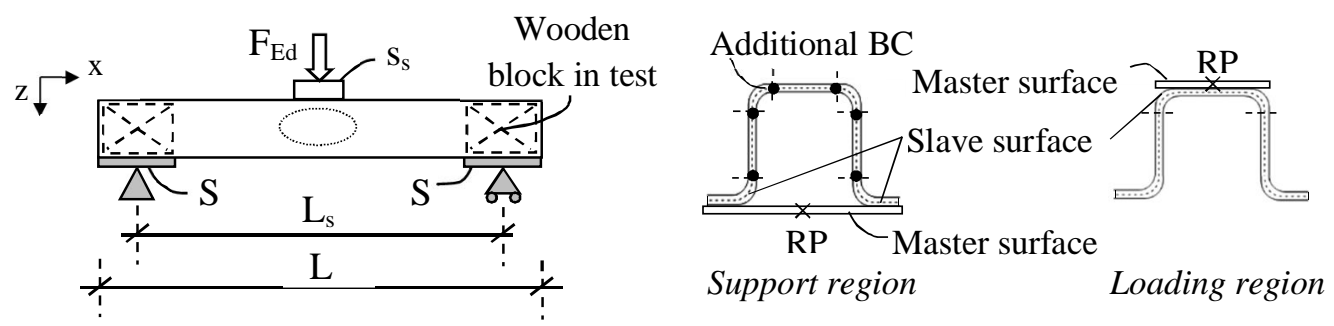

Fig. 2. Numerical model for IOF loading

\subsection{ASCE standard SEI/ASCE 8-02}

The web crippling resistance equations provided in SEI/ASCE 8-02 [5] standard for the design of hat sections under IOF loading are given in Eq. (4) and Eq.(5) for different conditions according to the bearing length-to-thickness ratio whereas the expression for EOF loading is given in Eq. (6). In these equations, the coefficients $C_{1}, C_{2}, C_{3}, C_{4}$ and $\mathrm{C}_{\theta}$ are defined in Eqs. (7-11). These expressions are given herein following EN 1993-13 [7] symbols and SI units for consistency reasons and apply if: $\mathrm{s}_{\mathrm{s}} / \mathrm{t} \leq 210 ; \mathrm{s}_{\mathrm{s}} / \mathrm{h} \leq 3.5$; beams with $\mathrm{r} / \mathrm{t} \leq 6$; and deck with $\mathrm{r} / \mathrm{t} \leq 7 ; \mathrm{h} / \mathrm{t} \leq 200 \sin \phi ; 45^{\circ} \leq \phi \leq 90^{\circ}$. Interaction effects for the combination of bending and web crippling at intermediate supports (IOF loading) are accounted for by means of Eq. (12) which may be rewritten as Eq. (13) following the same procedure described for the interaction formula provided in EN 1993-1-3 [7]. The corresponding resistance factor for web crippling and bending should be taken as $\phi_{\mathrm{w}}=0.7$ and $\phi_{\mathrm{b}}=0.85$, respectively.

$$
\begin{aligned}
& R_{w, R d}=6.9 \phi_{w} t^{2} C_{1} C_{2} C_{\theta}\left(538-0.74 \frac{h}{t}\right)\left(1+0.007 \frac{s_{s}}{t}\right) \text { if } \frac{s_{s}}{t} \leq 60 \\
& R_{w, R d}=6.9 \phi_{w} t^{2} C_{1} C_{2} C_{\theta}\left(538-0.74 \frac{h}{t}\right)\left(0.75+0.011 \frac{s_{s}}{t}\right) \text { if } \frac{s_{s}}{t}>60 \\
& R_{w, R d}=6.9 \phi_{w} t^{2} C_{3} C_{4} C_{\theta}\left(244-0.57 \frac{h}{t}\right)\left(1+0.01 \frac{s_{s}}{t}\right) \\
& C_{1}=\left(1.22-0.22 \frac{f_{y b}}{227.7}\right) \frac{f_{y b}}{227.7} \text { if } \frac{f_{y b}}{631.35} \leq 1 \text { or } C_{1}=1.69 \text { if } \frac{f_{y b}}{631.35}>1 \\
& C_{2}=\left(1.06-0.06 \frac{r}{t}\right) \leq 1
\end{aligned}
$$




$$
\begin{aligned}
& C_{3}=\left(1.33-0.33 \frac{f_{y b}}{227.7}\right) \frac{f_{y b}}{227.7} \text { if } \frac{f_{y b}}{458.85} \leq 1 \text { or } C_{3}=1.34 \text { if } \frac{f_{y b}}{458.85}>1 \\
& C_{4}=\left(1.15-0.15 \frac{r}{t}\right) \leq 1 \text { but not less than } 0.50 \\
& C_{\theta}=0.7+0.3(\phi / 90)^{2} \\
& \frac{1.07 F_{E d}}{\phi_{w} R_{w, R d}}+\frac{M_{E d}}{\phi_{b} M_{c, R d}} \leq 1.42 \\
& F_{E d}=1.327 /\left(\frac{1}{\phi_{w} R_{w, R d}}+\frac{L_{s}-s_{s}}{4 \phi_{b} M_{c, R d}}\right) \leq \min \left\{F_{E d}, 4 M_{c, R d} /\left(L_{s}-s_{s}\right)\right\}
\end{aligned}
$$

\section{Numerical modelling \\ 3.1 Modelled tests}

The finite element (FE) software ABAQUS was used to model 8 hat sections in grade EN 1.4509 (ferritic) stainless steel subjected to web crippling, including 4 tests under IOF loading and 4 tests under EOF loading which were performed at VTT Technical Research Centre of Finland [17]. The model was based on centreline dimensions (see Fig.1) determined from measured geometry reported in [17] as given in Table 3 where $h$ is the web height between the midlines of the flanges, $b$ is the flange width, $c$ is the flat part of the lip, $t$ is the thickness and $r_{m}$ is the bending radius measured from the midline. Important information is also provided in Table 3 by the beam labeling. Considering

\begin{tabular}{|c|c|c|c|c|c|c|c|c|c|c|}
\hline Beam & $\begin{array}{c}\mathrm{h} \\
(\mathrm{mm})\end{array}$ & $\begin{array}{c}\mathrm{b} \\
(\mathrm{mm})\end{array}$ & $\begin{array}{c}\mathrm{c} \\
(\mathrm{mm})\end{array}$ & $\begin{array}{c}\mathrm{t} \\
(\mathrm{mm})\end{array}$ & $\begin{array}{c}\mathrm{r}_{\mathrm{m}} \\
(\mathrm{mm})\end{array}$ & $\begin{array}{l}F_{u, \text { test }} \\
(\mathrm{kN})\end{array}$ & $\begin{array}{c}\mathrm{R}_{\mathrm{w}, \mathrm{u}, \mathrm{test}} \\
(\mathrm{kN})\end{array}$ & $\begin{array}{c}\mathrm{F}_{\mathrm{u}, \mathrm{num}} \\
(\mathrm{kN})\end{array}$ & $\begin{array}{c}\mathrm{R}_{\mathrm{w}, \mathrm{u}, \mathrm{num}} \\
(\mathrm{kN})\end{array}$ & $\begin{array}{l}\mathrm{F}_{\mathrm{u}, \text { test }} / \\
\mathrm{F}_{\mathrm{u}, \mathrm{num}}\end{array}$ \\
\hline ITH_10 & 71.09 & 72.89 & 24.17 & 0.99 & 1.65 & 10.01 & 5.00 & 10.19 & 5.09 & 0.982 \\
\hline ITH_15 & 70.73 & 70.56 & 24.11 & 1.53 & 1.9 & 20.73 & 10.37 & 21.04 & 10.70 & 0.969 \\
\hline ITH_20 & 70.08 & 69.72 & 24.02 & 1.99 & 2.4 & 34.84 & 17.42 & 34.99 & 17.50 & 0.996 \\
\hline ITH_30 & 69.95 & 68.86 & 23.82 & 2.95 & 4.25 & 55.01 & 27.51 & 57.89 & 28.95 & 0.951 \\
\hline ETH_-10 & 71.05 & 72.85 & 24.15 & 0.99 & 1.65 & 10.05 & 3.59 & 9.96 & 3.56 & 1.009 \\
\hline ETH_15 & 70.84 & 70.47 & 24.03 & 1.53 & 1.9 & 21.06 & 7.52 & 20.36 & 7.27 & 1.034 \\
\hline ETH_20 & 70.52 & 69.65 & 23.98 & 1.99 & 2.4 & 36.29 & 12.96 & 33.91 & 12.11 & 1.071 \\
\hline \multirow[t]{3}{*}{ ETH_30 } & 69.39 & 68.86 & 23.74 & 2.94 & 4.25 & 58.90 & 21.04 & 53.72 & 19.18 & 1.096 \\
\hline & & & & & & & & $\mathrm{Me}$ & & 1.011 \\
\hline & & & & & & & & $\mathrm{COV}$ & & 0.046 \\
\hline
\end{tabular}
ITH_10 as an example, I is the load configuration, TH stands for Top Hat and 10 is ten times the nominal thickness of the cross-section in $\mathrm{mm}$.

Table 3. Geometry of the modelled specimens [17] and comparison between test results and FE model

The overall length $\mathrm{L}$ of all the specimens was $399 \mathrm{~mm}$, the supports $\mathrm{S}$ were $50 \mathrm{~mm}$ length, the bearing length $\mathrm{s}_{\mathrm{s}}$ was $25 \mathrm{~mm}$ and the clear distance between the steel plate under the applied force and the end support in the EOF loading test, e, was $75 \mathrm{~mm}$ (see Figs 2 and 3). It should be noted that the configuration of these tests was intended to reproduce the web crippling response of continuous spans where the lips of the hat section are oriented upwards as shown in Fig.1. Hence, the applied local transverse forces satisfy EOF loading at the end of the continuous member (external supports) whereas interior supports are subjected to IOF loading. 
Table 3 also gives the ultimate applied load in the test [17] $\mathrm{F}_{\mathrm{u} \text {,test }}$ and the local transverse resistance per web $R_{w, u \text {,est }}$ which was determined according to $R_{w, u \text {,est }}=F_{u \text {,est }} / 2$ for IOF loading whereas for EOF loading, the expression $\left.\mathrm{R}_{\mathrm{w}, \mathrm{u} \text {, test }}=\left[\left(\mathrm{F}_{\mathrm{u}, \text { test }}\left[\mathrm{L}_{\mathrm{s}} \mathrm{e}-\mathrm{e}-\mathrm{S} / 2\right)\right]\right) / \mathrm{L}_{\mathrm{s}}\right] / 2$ applies, where $\mathrm{L}_{\mathrm{s}}$ is the span as shown in Fig.3.

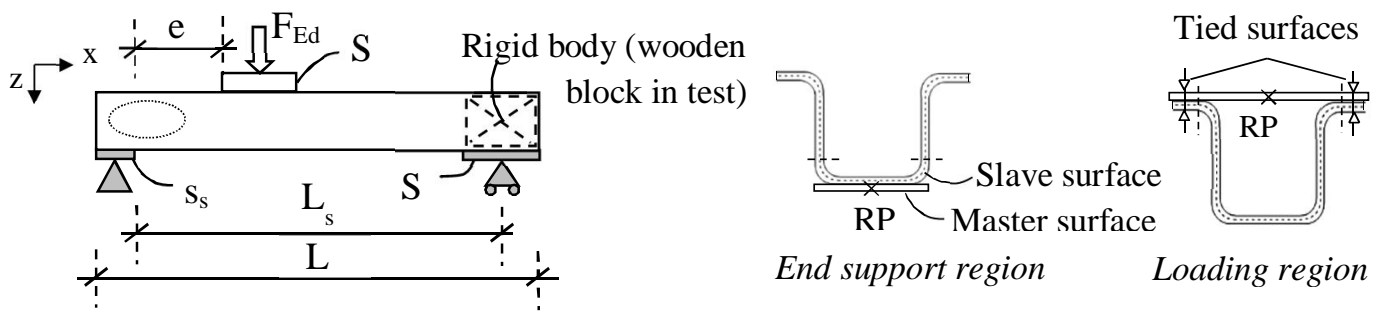

Fig. 3. Numerical model for EOF loading

\subsection{Mesh and material}

The geometry of these ferritic stainless steel hat sections was discretized using the fournode doubly curved shell element with reduced integration S4R. The employed mesh size used in the model was optimized to achieve accurate results while minimizing computational time; hence, a mesh size of $3 \times 3 \mathrm{~mm}$ was used for the flat parts of the cross-sections whereas a number of elements equals to ten times the nominal thickness was employed to model the corners.

The material properties of the tested specimens reported in [17] are given in Table 4, including the material Young modulus $\mathrm{E}$, the $0.2 \%$ proof stress $\sigma_{0.2}$, the ultimate stress and its corresponding ultimate strain, $\sigma_{\mathrm{u}}$ and $\varepsilon_{\mathrm{u}}$ respectively, and the first and second strain hardening parameters, $\mathrm{n}$ and $\mathrm{m}$ respectively. The whole stress-strain (engineering) curve was obtained using the compound two-stage Mirambell and Real material model [19], modified by Rasmussen [20] and included in Annex C of EN 1993-1-4 [6]. These material properties were incorporated into the FE model converting the stress-strain (engineering) curve into true stress and logarithmic plastic strain.

Table 4. Measured material properties of the modelled specimens [17]

\begin{tabular}{ccccccc}
\hline $\begin{array}{c}\text { Nominal } \\
\text { thickness }(\mathrm{mm})\end{array}$ & $\begin{array}{c}\mathrm{E} \\
(\mathrm{GPa})\end{array}$ & $\begin{array}{c}\sigma_{0.2} \\
(\mathrm{MPa})\end{array}$ & $\mathrm{n}$ & $\begin{array}{c}\sigma_{\mathrm{u}} \\
(\mathrm{MPa})\end{array}$ & $\mathrm{m}$ & $\varepsilon_{\mathrm{u}}$ \\
\hline 1 & 200 & 359 & 23.1 & 479 & 1.46 & 0.0170 \\
1.5 & 191 & 322 & 26.1 & 475 & 1.21 & 0.0160 \\
2 & 193 & 372 & 23.0 & 489 & 1.30 & 0.0164 \\
3 & 180 & 297 & 23.5 & 445 & 1.22 & 0.0160 \\
\hline
\end{tabular}

\subsection{Boundary conditions and loading}

For the case of the IOF loading (Category 2), the transverse load $F_{E d}$ was applied through a rigid plate $\left(s_{s}\right)$ controlled by a reference point (RP). All the degrees of freedom except the vertical translation were restrained in this RP and a vertical displacement was imposed to represent the loading. Contact pair (surface-to-surface) was used to model the interface between the rigid plate (master surface) and the flange of the cross-section (slave surface, extended up to the corners) assuming frictionless response in the tangential direction and hard response in the normal one. Two supports (S), which were also modelled as rigid plates, were placed on both edges in contact with the lips to model simply supported conditions. Their respective reference points (RP) were provided with appropriate boundary conditions to allow in-plane rotation. In the test arrangement [17], wooden blocks were placed within the cross-section to prevent 
possible local instabilities at the support regions. This was modelled by restraining the vertical and horizontal translations as well as the rotation about the x-axis at the flat regions of the webs and the flange adjacent on either side of the corners over the length of the supports S. All these details are given in Fig. 2.

Regarding EOF loading (Category 1), the transverse load $\mathrm{F}_{\mathrm{Ed}}$ was also applied through a rigid plate (S), similarly to the IOF loading. While testing [17], screw clamps were used to join this plate and the lips of the hat section together, which was modelled by tying the surfaces in contact. The end bearing support $\left(\mathrm{s}_{\mathrm{s}}\right)$ was also modelled as a rigid plate and contact pair was used to model the interface with the specimen. A wooden block was placed within the cross-section at the further end support to prevent distortional deformation in the test [17]. The geometry of the cross-section over this support was modelled as a rigid body controlled by a reference point (RP) in its center of mass. Inplane rotation was allowed at the bearing support $\left(\mathrm{s}_{\mathrm{s}}\right)$ and in the the rigid body (end support). All these details are given in Fig.3.

\subsection{Verification of the numerical model}

Figs 4 and 5 present the load-displacement response recorded in the test [17] and obtained with the numerical model for IOF and EOF loading, respectively, whereas ultimate applied numerical loads $\mathrm{F}_{\mathrm{u} \text {,num }}$ and resistances per web $\mathrm{R}_{\mathrm{w}, \mathrm{u} \text {,num }}$ determined as described in sub-section 3.1 are given in Table 3. Excellent good agreement between test results and models was achieved, particularly for the ultimate predicted load for both loading configurations with mean test-to-numerical ratio of 1.011 and coefficient of variation (COV) of 0.046. Experimental and numerical failure modes for both IOF and EOF loading are shown in Figs 6 and 7, respectively. In both cases, the numerical models accurately capture the experimental failure mode. This numerical model is therefore deemed reliable and suitable to perform parametric studies. The discrepancy between the experimental and numerical stiffness, particularly in the EOF curves, was also observed in existing studies [21, 22], which was associated with the sensitivity of the FE model to the boundary conditions and initial imperfections of the member owing to the thin-walled nature of the cross-section.

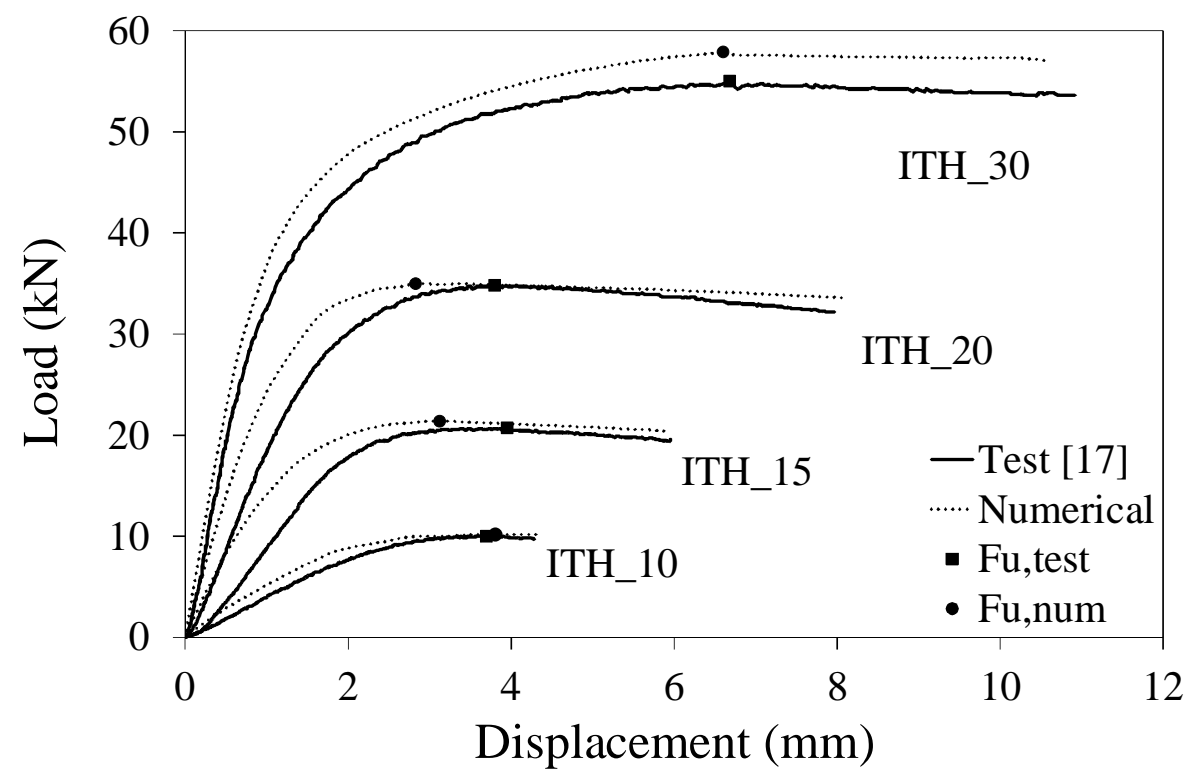

Fig. 4. Load-displacement response for beams subjected to IOF loading 


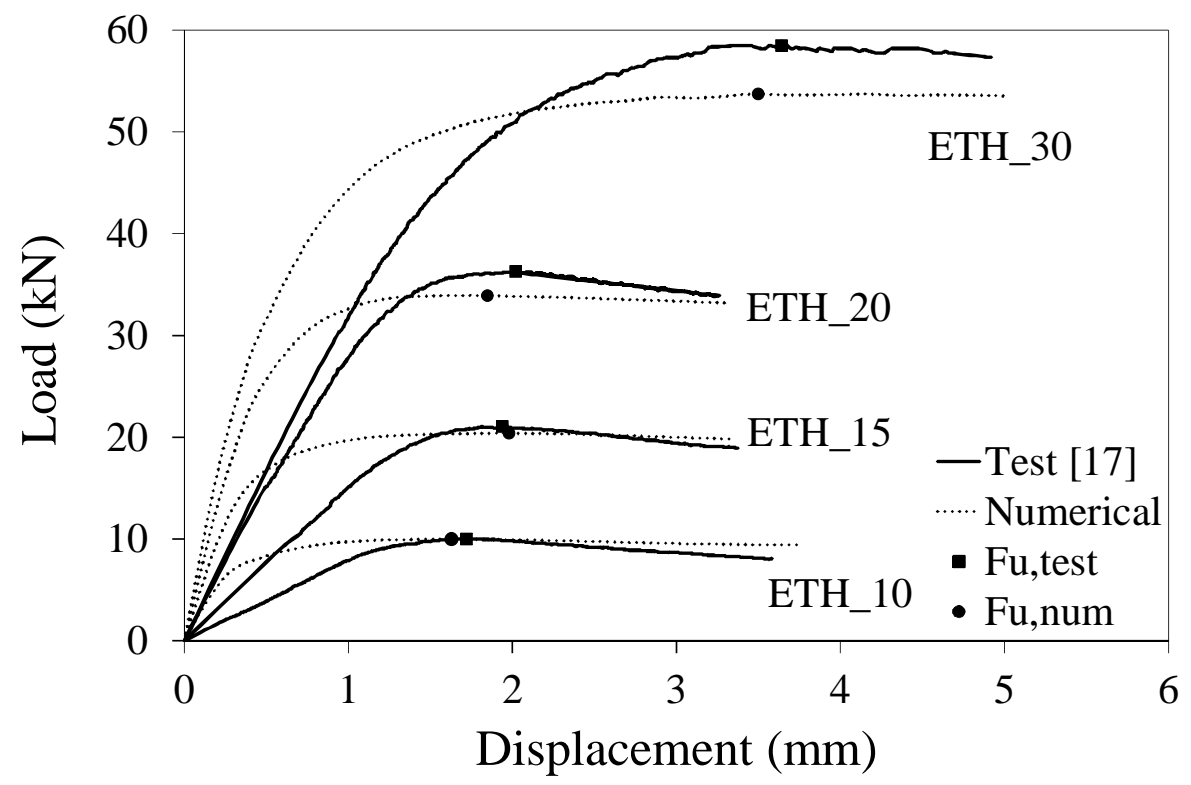

Fig. 5. Load-displacement response for beams subjected to EOF loading
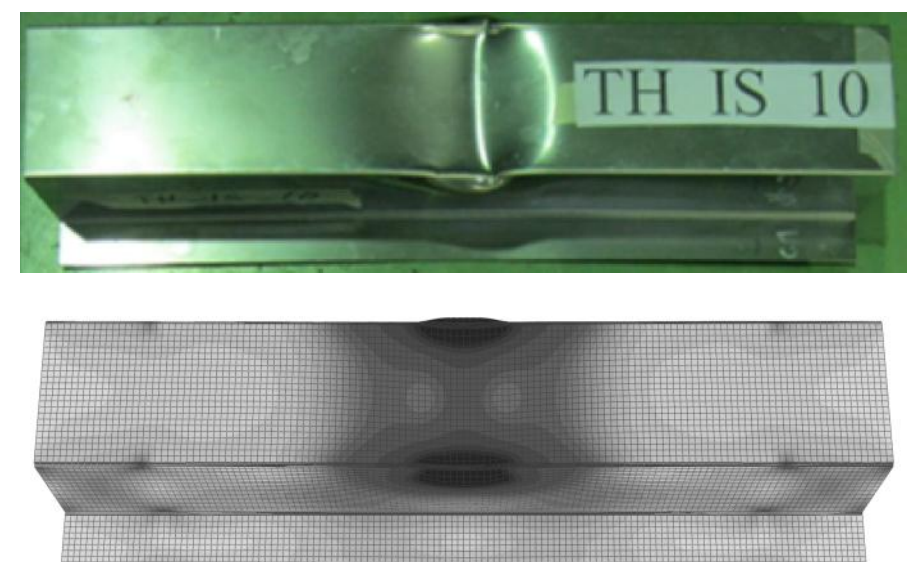

Fig. 6. Typical web crippling failure mode for IOF loading (ITH_10) [17]
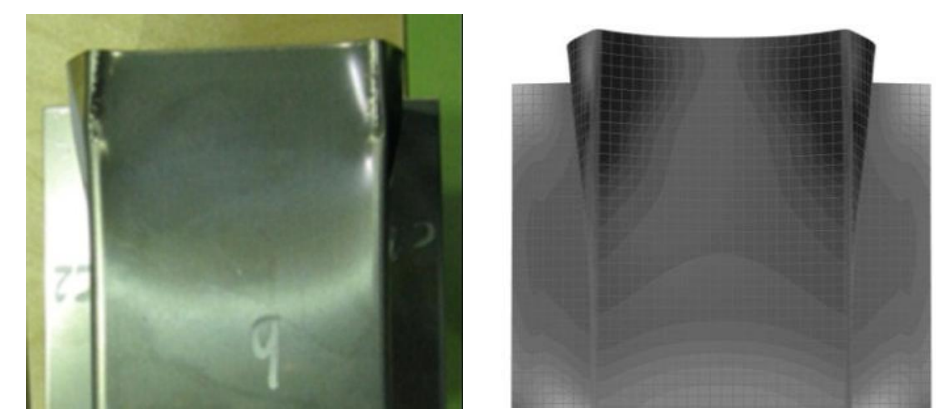

Fig. 7. Typical web crippling failure mode for EOF loading (ETH_10) [17]

3.5 Cross-section geometries and load configurations for the parametric study

Having validated the numerical model, an extensive parametric study was conducted to generate numerical data over different geometries and investigate the web crippling behaviour of hat sections under both IOF (Category 2) and EOF (Category 1) loading conditions. The study was performed for ferritic and austenitic stainless steels with the 
following material properties based on average values given in EN 1993-1-4 [6]: E=200 $\mathrm{GPa}, \sigma_{0.2}=350 \mathrm{MPa}, \mathrm{n}=15, \sigma_{\mathrm{u}}=450 \mathrm{MPa}, \mathrm{m}=3$ and $\varepsilon_{\mathrm{u}}=0.15$ for ferritic stainless steel, while $\mathrm{E}=193 \mathrm{GPa}, \sigma_{0.2}=445 \mathrm{MPa}, \mathrm{n}=7, \sigma_{\mathrm{u}}=700 \mathrm{MPa}, \mathrm{m}=3.4$ and $\varepsilon_{\mathrm{u}}=0.42$ for austenitic stainless steel. The parametric study included 7 different hat section geometries with the following centreline dimension in $\mathrm{mm}\left(\mathrm{h} \times \mathrm{b} \times \mathrm{c} \times \mathrm{t} \times \mathrm{r}_{\mathrm{m}}\right): 30 \times 30 \times 17 \times 1 \times 1.5$, $50 \times 50 \times 20 \times 1.5 \times 2, \quad 80 \times 50 \times 20 \times 1.5 \times 2, \quad 100 \times 50 \times 20 \times 1.5 \times 2, \quad 50 \times 80 \times 20 \times 1.5 \times 2$, $100 \times 100 \times 25 \times 1.5 \times 2$ and $70 \times 70 \times 25 \times 1.5 \times 2$. For all these geometries, the length of the member $\mathrm{L}$, the bearing plate $\mathrm{s}_{\mathrm{s}}$, and the support plates $\mathrm{S}$, were $400 \mathrm{~mm}, 25 \mathrm{~mm}$ and 50 $\mathrm{mm}$ respectively. Regarding the clear distance e for the EOF loading, this was set out as $\mathrm{e}=75 \mathrm{~mm}$. Additional specimens were modelled to study the influence of various parameters on the web crippling strength, including: the thickness $(\mathrm{t}=0.5 \mathrm{~mm}, 0.75 \mathrm{~mm}$, $1 \mathrm{~mm}$ and $2 \mathrm{~mm}$ ); the bearing length $\left(\mathrm{s}_{\mathrm{s}}=12.5 \mathrm{~mm}\right.$ and $50 \mathrm{~mm}$ for IOF loafing, and $\mathrm{s}_{\mathrm{s}}=10 \mathrm{~mm}$ and $35 \mathrm{~mm}$ for EOF loading); the bending radius $\left(\mathrm{r}_{\mathrm{m}}=1.5 \mathrm{~mm}, 2.5 \mathrm{~mm}\right.$ and 3 $\mathrm{mm})$; the length $(\mathrm{L}=600 \mathrm{~mm}$ and $\mathrm{L}=800 \mathrm{~mm})$; a clear distance $\mathrm{e}=150 \mathrm{~mm}$ was also studied for the EOF loading.

\section{Strength curves controlled by slenderness-based functions \\ 4.1 Basis of the method}

The concept underpinning the so-called strength curves $\chi(\bar{\lambda})$ is that structural steel members (or cross-sections) fail in a way involving buckling and yielding relating the reduction factor $\chi$ to a relative slenderness $\bar{\lambda}$. Unlike the current web crippling design equations, which are purely empirical in nature, this slenderness-based design approach combines both theoretical and empirical basis and therefore, leads to a better understanding of the underlying engineering principles involved in the formulation. Various strength curves are currently given in the design codes for the verification of different instabilities including local buckling, shear buckling, patch loading and global buckling among others.

The suitability of this method based on strength curves $\chi(\bar{\lambda})$ for web crippling design was recently investigated by Duarte and Silvestre [23] on cold-formed carbon unstiffened C-sections. The success for such sections opens the way for its extension to cover other section typologies and materials. Hence, the method is extended herein for web crippling design of stainless steel hat sections following previous research on the same topic [24].

The base curve (strength curve) of this method, given in Eq. (14) in the general expression where the coefficients $\mathrm{A}$ and $\mathrm{B}$ may be derived by regression analysis of data, provides a continuos relationship between the reduction factor $\chi$ and the relative slenderness $\bar{\lambda}$ given by Eq. (15), where $R_{\mathrm{w}, \mathrm{cr}}$ and $\mathrm{R}_{\mathrm{w}, \mathrm{pl}}$ are the elastic critical buckling resistance and the plastic resistance per web, respectively. The web crippling resistance per web $R_{\mathrm{w}, \mathrm{u}}$ may be then determined applying the reduction factor $\chi$ to the plastic resistance $\mathrm{R}_{\mathrm{w}, \mathrm{pl}}$ as defined by Eq. (16).

$$
\begin{aligned}
& \chi=\frac{A}{\bar{\lambda}^{B}} \leq 1 \\
& \bar{\lambda}=\sqrt{\frac{R_{w, p l}}{R_{w, c r}}} \\
& R_{w, u}=\chi R_{w, p l}
\end{aligned}
$$




\subsection{Data required for the design method}

The determination of the coefficients $\mathrm{A}$ and $\mathrm{B}$ within the strength curve utilises data over a $\chi-\bar{\lambda}$ space. While Eq. (15) is used to obtain values over the horizontal axis, the reduction factor $\chi$, taken as Eq. (16) and rewritten as $\chi=R_{w, u} / R_{w, p l}$, is used for the vertical axis. Consequently, three different resistances are required upon which to base the development of the design method: the web crippling resistance $\mathrm{R}_{\mathrm{w}, \mathrm{u}}$; the elastic critical buckling resistance $\mathrm{R}_{\mathrm{w}, \mathrm{cr}}$; and the plastic resistance $\mathrm{R}_{\mathrm{w}, \mathrm{p} \text {. }}$. It should be noted that while the web crippling resistance $\mathrm{R}_{\mathrm{w}, \mathrm{u}}$ may be obtained from tests (or numerical simulations), both elastic critical buckling resistance $R_{w, c r}$ and plastic resistance $R_{w, p l}$ may only be determined numerically.

The validated numerical model described previously in section 3 was therefore used to obtain such resistances for the aforementioned cross-section geometries and load cases described in sub-section 3.5. The three resistances $R_{w, c r}, R_{w, p l}$ and $R_{w, u}$ were determined performing three types of analyses on every single model [23, 24]: (1) elastic buckling analyses to determine the elastic critical buckling resistances $\mathrm{R}_{\mathrm{w}, \mathrm{cr}}$; (2) first order plastic analyses to obtain the plastic resistances $\mathrm{R}_{\mathrm{w}, \mathrm{pl}}$; and (3) geometrical and material nonlinear analyses for the determination of the ultimate web crippling resistances $R_{\mathrm{w}, \mathrm{u}}$. A total of 350 numerical analyses were conducted.

\subsection{Results from the analyses}

The obtained numerical results, including the generated models in the parametric study and the modelled tests are presented in Figs 8 and 9 for IOF and EOF loading, respectively. In Figs 8 and 9, the reduction factor $\chi$, determined as the ultimate numerical web crippling resistance $\mathrm{R}_{\mathrm{w}, \mathrm{u}, \mathrm{num}}$ divided by the numerical plastic resistance $\mathrm{R}_{\mathrm{w}, \mathrm{pl} \text {,num }}$, is plotted against the relative slenderness $\bar{\lambda}$ obtained as the squared root of the numerical plastic resistance $R_{w, p l, n u m}$ to numerical critical resistance $R_{w, c r, n u m}$ ratio as given by Eq. (15). Strength curves applicable to other cross-sections, including those proposed by Duarte and Silvestre [23] for cold-formed carbon steel unstiffened Csections and given in EN 1993-1-5 [25] for carbon steel plate girders (I-sections) subjected to patch loading are also depicted in Figs 8 and 9 so that their suitability for application to cold-formed stainless steel hat sections could be assessed.

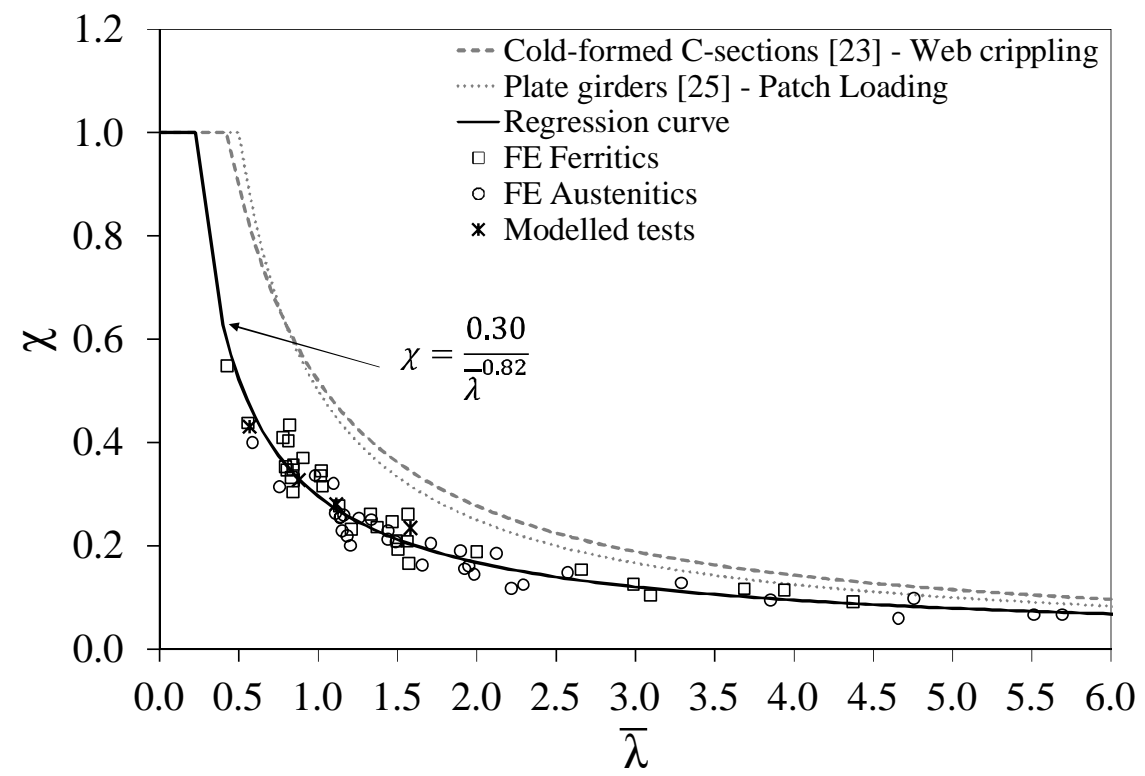

Fig. 8. Reduction factor versus relative slenderness (based on numerical results) for IOF loading 


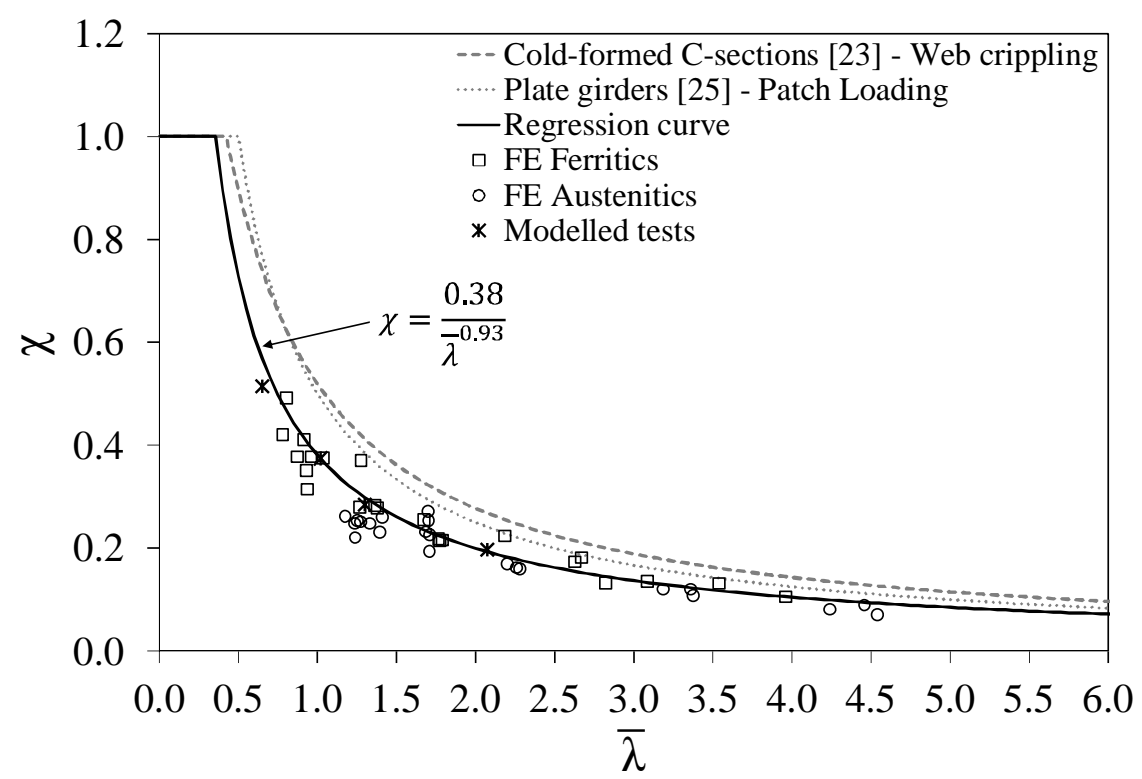

Fig. 9. Reduction factor versus relative slenderness (based on numerical results) for EOF loading

Three main conclusions can be drawn from Figs 8 and 9. Firstly, the resulting points display a curved trend of decreasing reduction factor $\chi$ with increasing relative slenderness $\bar{\lambda}$. The regression curves (strength curves) yielding the equations shown in the corresponding figures represent this continuous relationship between reduction factor $\chi$ and relative slenderness $\bar{\lambda}$. Secondly, all the generated data lay significantly below the strength curves for web crippling design of cold-formed carbon unstiffened C-sections [23] and patch loading design of plated girders [25], reflecting a different web crippling response of stainless steel hat sections for both IOF and EOF loading. And finally, regarding the material effect, austenitic and ferritic stainless steel appeared to perform similarly, thus, there is no need to derive different strength curves for different stainless steels.

For practical application of the adjusted strength curves shown in Figs 8 and 9, predictive models for both elastic critical buckling resistance $R_{w, c r}$ and the first order plastic load $\mathrm{R}_{\mathrm{w}, \mathrm{pl}}$ may be derived. Additionally, these strength curves should be statistically validated so that they satisfy the partial safety factor recommended in EN 1993-1-4 [6] for stainless steels $\left(\gamma_{\mathrm{M} 1}=1.1\right)$. Both tasks are developed in the following section.

\section{Proposed strength curves and predictive models 5.1 Predictive model for $R_{w, c r}$}

The proposed predictive model for the elastic critical buckling resistance $R_{\mathrm{w}, \mathrm{cr} \text {,pred }}$ stems from classical elastic theory of instability for a plate loaded with a concentrated in-plane force at the edge given in Eq. (17) where the dimensionless buckling coefficient $\mathrm{k}_{\mathrm{F}}$ may be derived for a given plate geometry and boundary conditions [23, 26, 27]. The derived expression for $\mathrm{k}_{\mathrm{F}}$ is given in Eq. (18) where coefficients were determined by regression analysis accounting both generated models in the parametric study and modelled tests. Note that although the key controlling parameters in the dimensionless buckling coefficient $\mathrm{k}_{\mathrm{F}}$ are similar for both IOF and EOF loading, two different expressions are proposed. The symbols of these expressions are defined by reference to Figs 1-3. 
Tables 5 and 6 compare the numerical elastic critical resistances $R_{w, c r, n u m}$ with the predicted ones using this proposed model $\mathrm{R}_{\mathrm{w}, \mathrm{cr} \text {,pred }}$ for the modelled tests alone under IOF and EOF loading, respectively. Table 7 presents the results for the generated numerical models in terms of mean numerical-to-predicted ratio. In Tables 5-7, results show that predicted resistances agree with the numerical results with a mean numericalto-predicted ratio very close to unity and fairly reduced coefficient of variation (COV). Figs 10 and 11 show a comparison of the predictions to all the data for IOF and EOF loading, respectively, where distinction between materials is made (FE Ferritics and FE Austenitics).

$$
\begin{gathered}
R_{w, \text { cr,pred }}=k_{F} \frac{\pi^{2} E t^{3}}{12\left(1-v^{2}\right) h} \\
k_{F}= \begin{cases}4.9-1.6\left(\frac{b}{h}\right)-0.006\left(\frac{L}{h}\right)^{2}+6.6\left(\frac{s_{s}}{L}\right) & \text { For IOF loading } \\
1.85-0.75\left(\frac{b}{h}\right)+1.75\left(\frac{s_{s}}{h}\right) & \text { For EOF loading }\end{cases}
\end{gathered}
$$

Table 5. Comparison between numerical results and predictive models for the modelled tests under IOF loading

\begin{tabular}{ccccccc}
\hline Beam & $\begin{array}{c}\mathrm{R}_{\mathrm{w}, \mathrm{cr} \text { num }} \\
(\mathrm{kN})\end{array}$ & $\begin{array}{c}\mathrm{R}_{\mathrm{w}, \mathrm{cr}, \mathrm{pred}} \\
(\mathrm{kN})\end{array}$ & $\begin{array}{c}\mathrm{R}_{\mathrm{w}, \mathrm{pl} \text {,num }} \\
(\mathrm{kN})\end{array}$ & $\begin{array}{c}\mathrm{R}_{\mathrm{w}, \mathrm{pl} \text {,pred }} \\
(\mathrm{kN})\end{array}$ & $\begin{array}{c}\mathrm{R}_{\mathrm{w}, \mathrm{cr}, \text { num }} / \\
\mathrm{R}_{\mathrm{w}, \mathrm{cr}, \text { pred }}\end{array}$ & $\begin{array}{c}\mathrm{R}_{\mathrm{w}, \mathrm{pl} \text {,num }} / \\
\mathrm{R}_{\mathrm{w}, \mathrm{pl}, \text { pred }}\end{array}$ \\
\hline ITH_10 & 8.62 & 8.70 & 21.73 & 21.28 & 0.991 & 1.021 \\
ITH_15 & 30.94 & 30.86 & 38.12 & 31.61 & 1.003 & 1.206 \\
ITH_20 & 67.70 & 69.10 & 53.41 & 50.41 & 0.980 & 1.059 \\
ITH_30 & 195.97 & 209.77 & 67.20 & 52.41 & 0.934 & 1.282 \\
\hline & & & & Mean & 0.977 & 1.142 \\
& & & & COV & 0.026 & 0.093 \\
\hline
\end{tabular}

Table 6. Comparison between numerical results and predictive models for the modelled

\begin{tabular}{|c|c|c|c|c|c|c|}
\hline Beam & $\begin{array}{c}\mathrm{R}_{\mathrm{w}, \mathrm{cr}, \mathrm{num}} \\
(\mathrm{kN})\end{array}$ & $\begin{array}{c}\mathrm{R}_{\mathrm{w}, \mathrm{cr}, \mathrm{pred}} \\
(\mathrm{kN})\end{array}$ & $\begin{array}{c}\mathrm{R}_{\mathrm{w}, \mathrm{pl}, \mathrm{num}} \\
(\mathrm{kN})\end{array}$ & $\begin{array}{c}\mathrm{R}_{\mathrm{w}, \mathrm{pl} \text {,pred }} \\
(\mathrm{kN})\end{array}$ & $\begin{array}{l}\mathrm{R}_{\mathrm{w}, \mathrm{cr}, \text { num }} / \\
\mathrm{R}_{\mathrm{w}, \mathrm{cr}, \text { pred }}\end{array}$ & $\begin{array}{l}\mathrm{R}_{\mathrm{w}, \mathrm{pl} \text {,num }} / \\
\mathrm{R}_{\mathrm{w}, \mathrm{pl} \text {,pred }}\end{array}$ \\
\hline ETH_10 & 4.17 & 4.14 & 17.91 & 16.96 & 1.007 & 1.056 \\
\hline ETH_15 & 15.21 & 15.08 & 25.71 & 23.97 & 1.008 & 1.072 \\
\hline ETH_20 & 33.05 & 33.88 & 34.29 & 34.22 & 0.976 & 1.002 \\
\hline \multirow[t]{3}{*}{ ETH_30 } & 95.76 & 104.05 & 40.48 & 41.56 & 0.920 & 0.974 \\
\hline & & & & Mean & 0.978 & 1.026 \\
\hline & & & & $\mathrm{COV}$ & 0.036 & 0.038 \\
\hline
\end{tabular}
tests under EOF loading

Table 7. Comparison between numerical results and predictive models for the generated models in the parametric study

\begin{tabular}{ccccccc}
\hline & & \multicolumn{3}{c}{$\mathrm{R}_{\mathrm{w}, \mathrm{pl}, \text { num }} / \mathrm{R}_{\mathrm{w}, \mathrm{pl} \text {,pred }}$} \\
\hline & $\mathrm{R}_{\mathrm{w}, \text { cr,num }} / \mathrm{R}_{\mathrm{w}, \mathrm{cr}, \text { pred }}$ & \multicolumn{2}{c}{ Ferritics } & \multicolumn{2}{c}{ Austenitics } \\
\hline & IOF & EOF & IOF & EOF & IOF & EOF \\
\hline Mean & 0.991 & 1.00 & 1.134 & 1.098 & 1.334 & 1.334 \\
COV & 0.035 & 0.015 & 0.176 & 0.226 & 0.205 & 0.241 \\
\hline
\end{tabular}




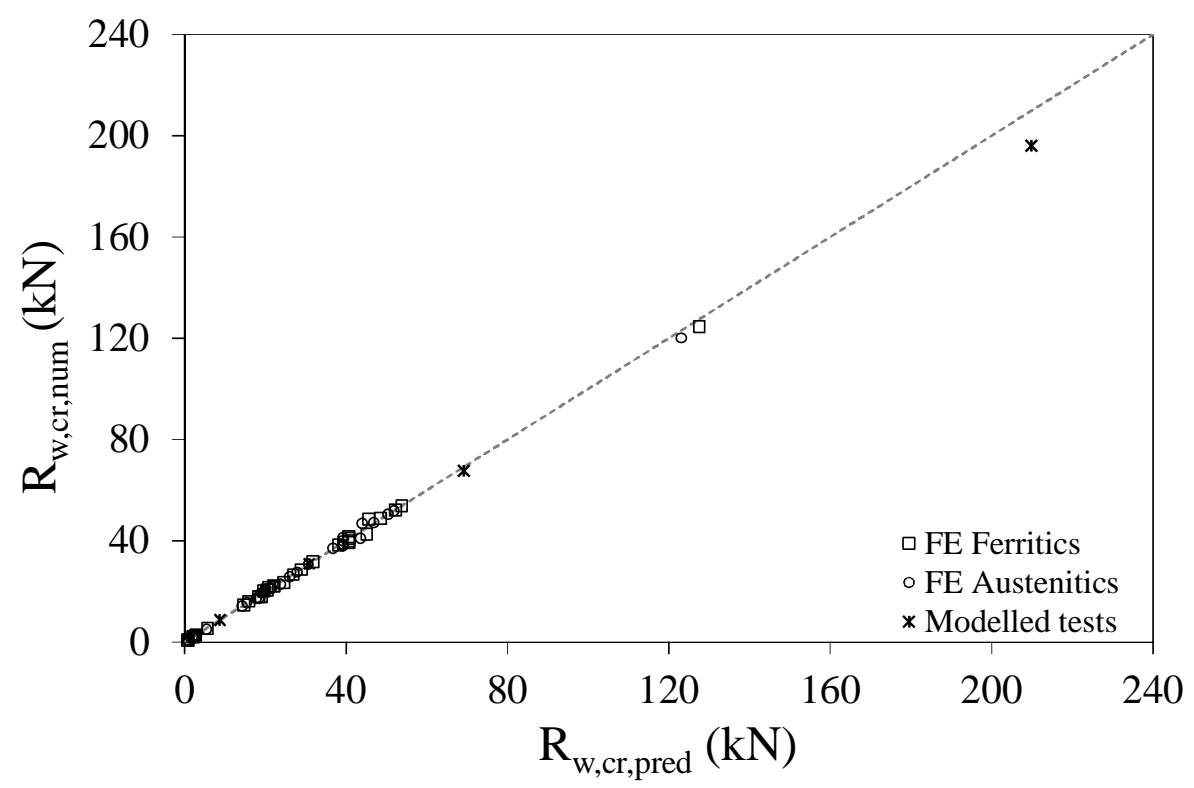

Fig. 10. Comparison between numerical and predicted elastic critical resistances for IOF loading

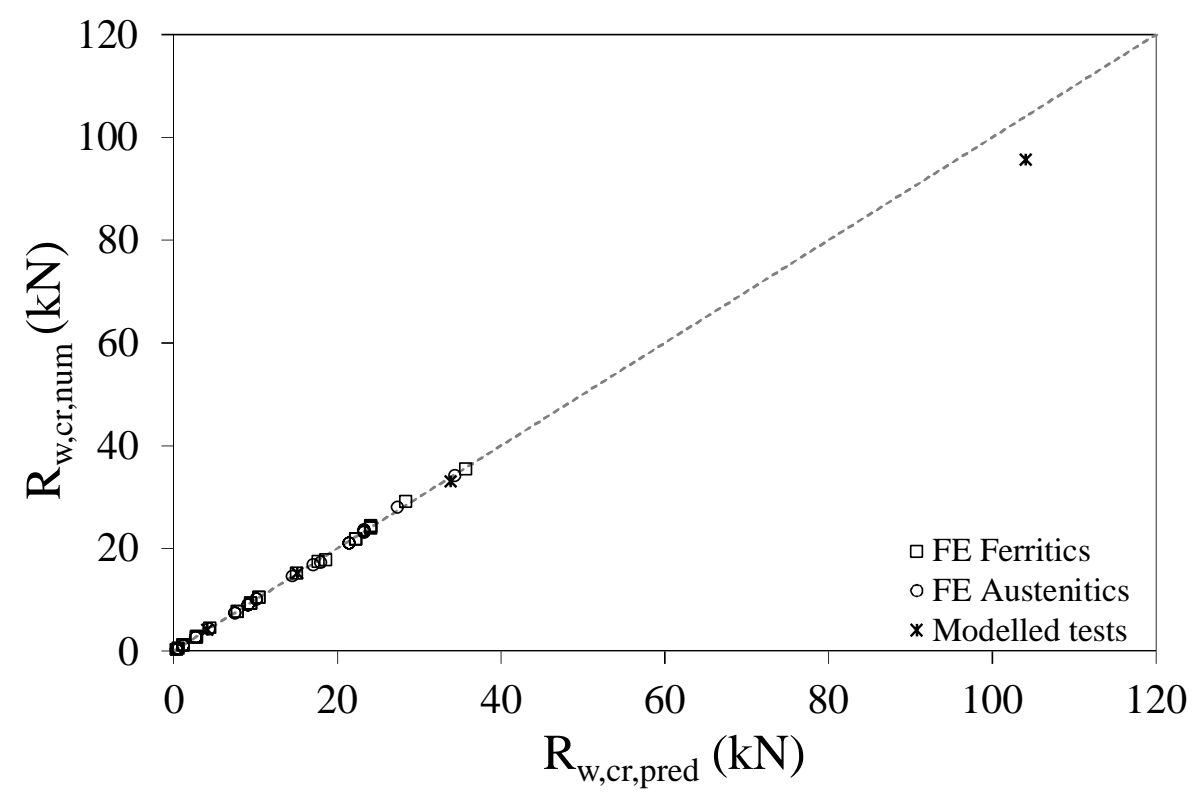

Fig. 11. Comparison between numerical and predicted elastic critical resistances for EOF loading

\subsection{Predictive model for $\mathbf{R}_{\mathrm{w}, \mathrm{pl}}$}

The plastic mechanism model proposed in [28] for cold-formed unstiffened C-sections is adapted herein for cold-formed hat sections as the predictive model of the first order plastic resistance per web $\mathrm{R}_{\mathrm{w}, \mathrm{pl} \text {,pred. }}$ Given the localized nature of the failure mode, the observed plastic mechanisms in the numerical analyses resemble the assumed plastic mechanism model regardless of the cross-sectional geometry. Other plastic mechanism models derived from yield lines for square hollow sections [29, 30, 31] as well as models based on plastic hinges $[27,32]$ are available in the literature.

The basis of the assumed plastic mechanism model, as shown in Fig. 12, is that the concentrated load applied over a bearing length on the flange $\mathrm{s}_{\mathrm{s}}$ can be idealized as a local eccentric load $\mathrm{R}_{\mathrm{w} \text {,pl,pred }}$ given in Eq. (19), inducing a plastic hinge per unit length 
$\mathrm{M}_{\mathrm{pl}, \mathrm{ly}}$ along the yield line $\mathrm{l}_{\mathrm{y}}$ as given in Eq. (20). Hence, the key parameter to adjust is this yield line length $1_{\mathrm{y}}$. A regression analysis accounting all the data lead to Eq. (21) where distinction is also made between load conditions and symbols are defined by reference to Figs 1-3. It should be noted that, unlike the adjusted strength curves and derived elastic critical buckling resistance model, this plastic resistance model includes a material correction factor $\mathrm{m}$, allowing for the attainment of higher plastic resistances for material with higher ductility. A value of $m=1$ for ferritic stainless steel and $m=1.15$ for austenitic stainless steel provided good agreement between predicted $R_{w, p l, p r e d}$ and numerical $\mathrm{R}_{\mathrm{w}, \mathrm{pl} \text {,num }}$ resistances as shown in Figs 13 and 14 for IOF and EOF loading, respectively. Note that in both figures, most of the predicted plastic resistances are placed on the safe side for both materials (FE Ferritics and FE Austenitics) accounted in the study.
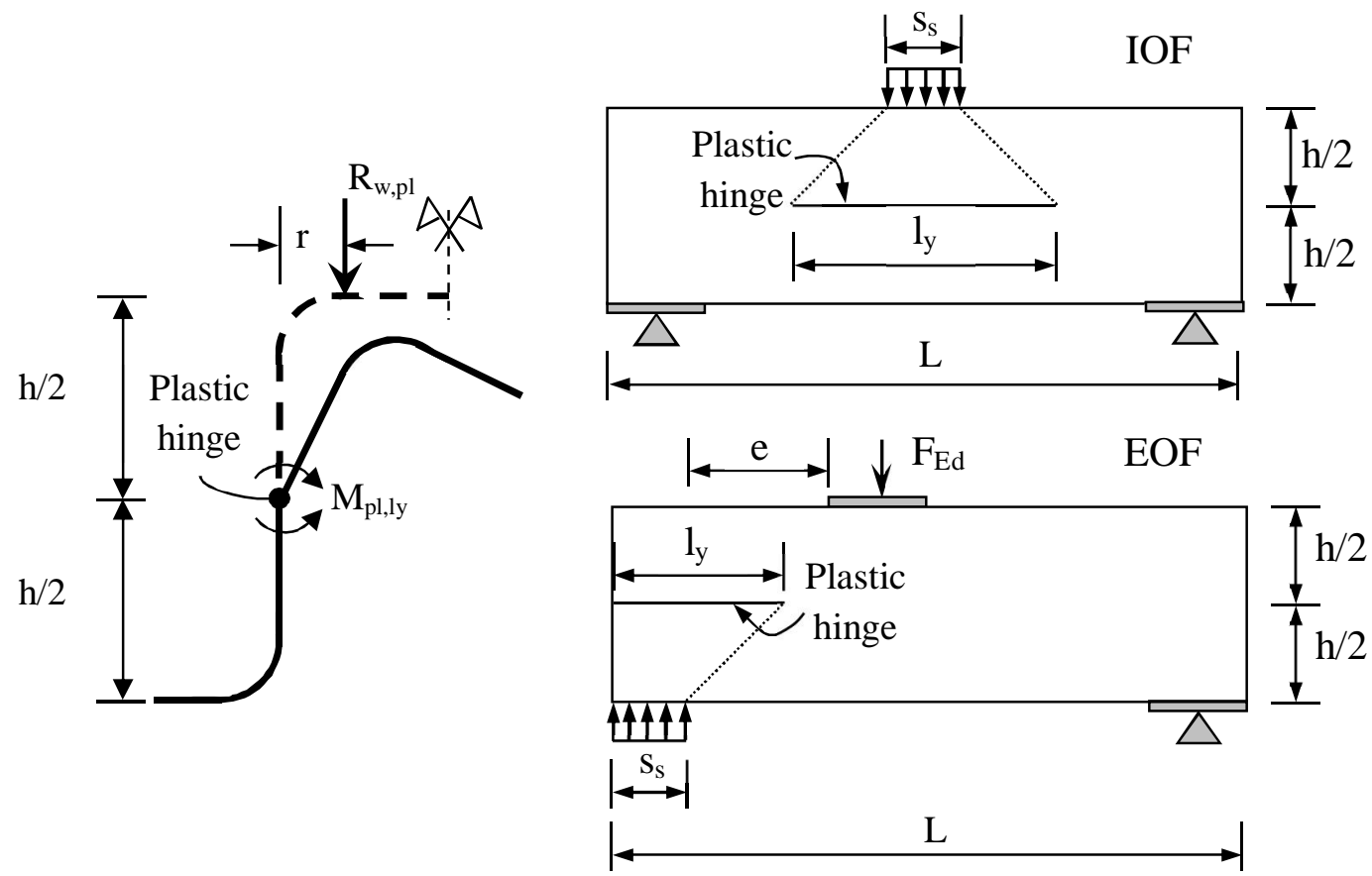

Fig. 12 Adopted plastic mechanism model [28] for hat sections

$$
\begin{aligned}
& R_{w, p l, p r e d}=\frac{M_{p l, l y} l_{y}}{r} \\
& M_{p l, l y}=\frac{\sigma_{0.2} t^{2}}{4}
\end{aligned}
$$

$l_{y}= \begin{cases}\left(s_{s}+h\right) m\left[\frac{2 r}{t}+\frac{5 b}{L}-0.55\right] & \text { For IOF loading } \\ \left(s_{s}+h / 2\right) m\left[2.2-6.2 \frac{\sqrt{r^{2}+t^{2}}}{t}+\frac{6.3 r}{t}+\frac{0.6 L}{e}\right] & \text { For EOF loading }\end{cases}$

Tables 5 and 6 give the predicted first order plastic resistances per web $R_{w, p l, p r e d}$ determined using this proposed predictive model for the modelled tests alone subjected to IOF and EOF loading, respectively. Regarding generated numerical models in the parametric study, only key statistical results based on mean numerical-to-predicted ratio and coefficient of variation $(\mathrm{COV})$ are shown in Table 7 where distinction is made between materials. 


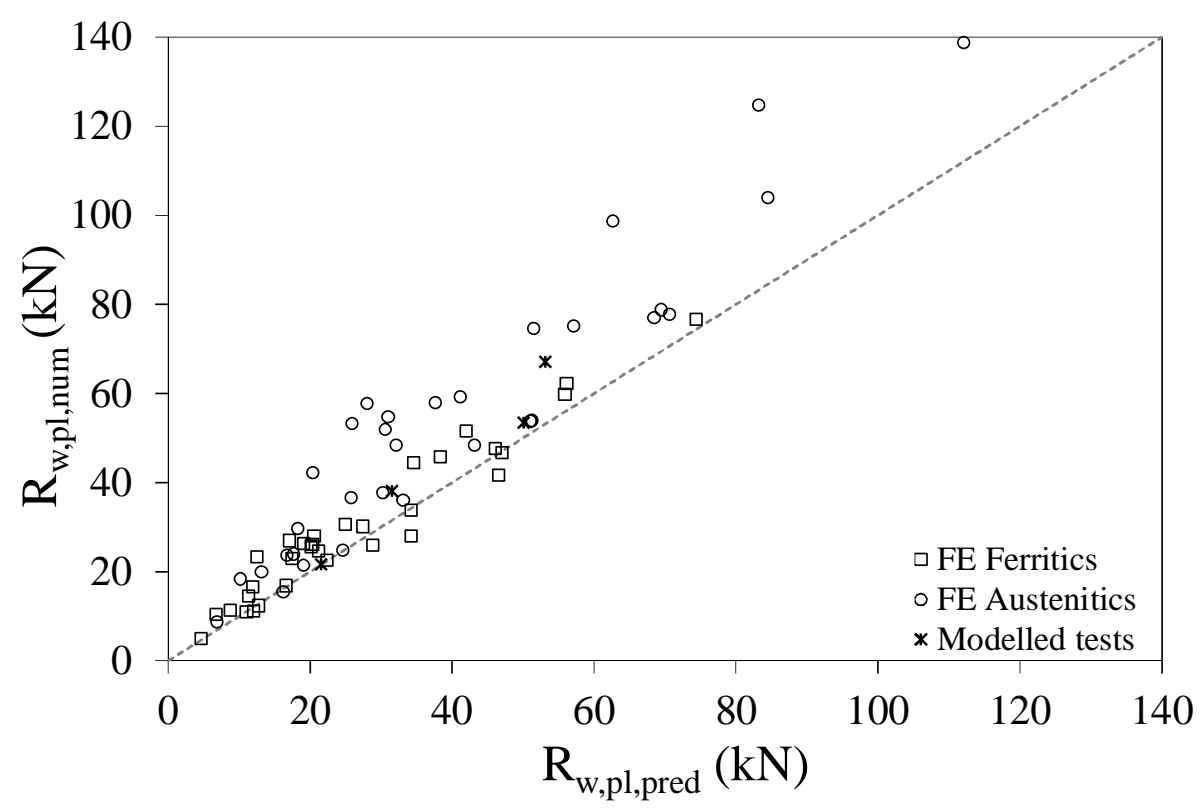

Fig. 13. Comparison between numerical and predicted plastic resistances for IOF loading

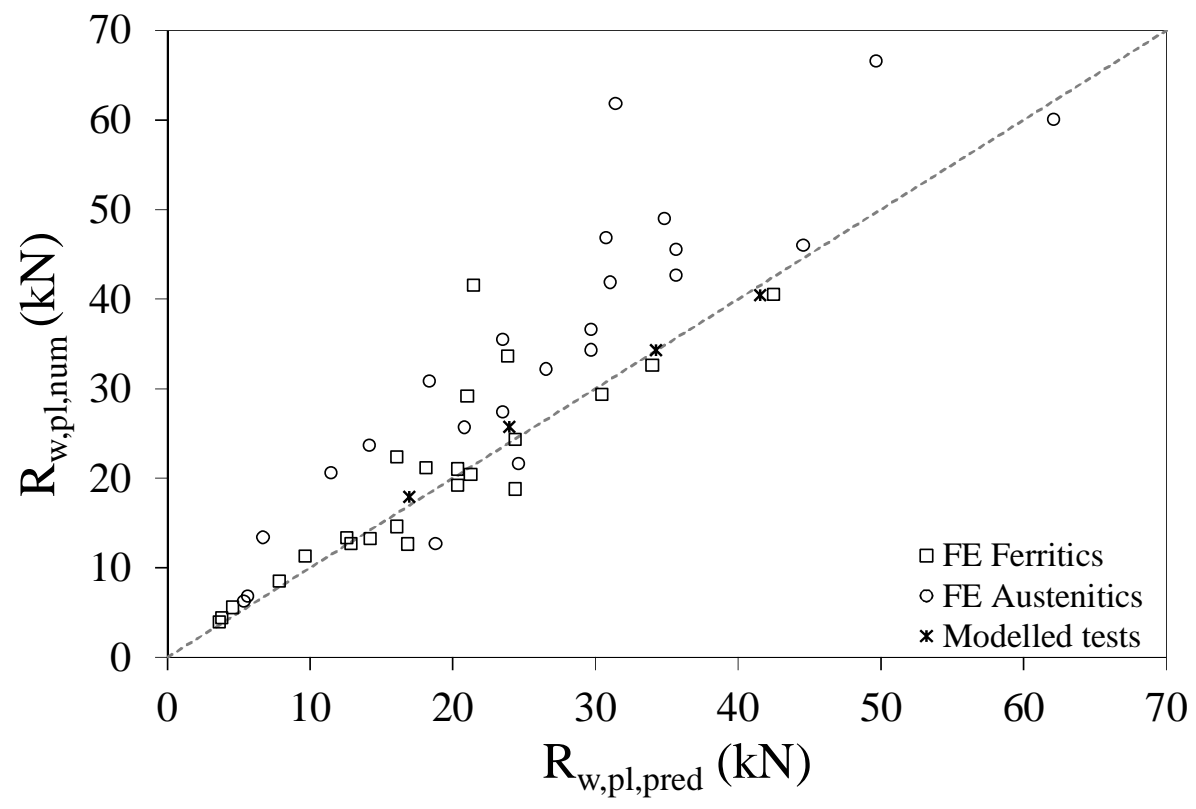

Fig. 14. Comparison between numerical and predicted plastic resistances for EOF loading

\subsection{Proposed strength curves and statistical validation}

Having adjusted predictive models for the elastic critical strength $R_{\mathrm{w}, \mathrm{cr} \text {,pred }}$ and the first order plastic resistance $\mathrm{R}_{\mathrm{w}, \mathrm{pl} \text {,pred }}$ given in the set of Eqs (17-18) and Eqs (19-21), respectively, these models are therefore used to derive practical strength curves for web crippling design of stainless steel hat sections. To this end, the predicted values provided by the corresponding predictive models for the elastic critical strength $R_{\mathrm{w}, \mathrm{cr} \text {,pred }}$ and the first order plastic resistance $\mathrm{R}_{\mathrm{w}, \mathrm{pl} \text {,pred }}$ are used to replace the corresponding numerical values which had been used to determine the relationship between the reduction factor $\chi$ and relative slenderness $\bar{\lambda}$ in previous section (Figs 8 and 9). Hence, the new reduction factor $\chi$ is determined as the ultimate numerical web crippling resistance $R_{\mathrm{u}, \mathrm{w}, \mathrm{num}}$ divided by the predicted plastic resistance $\mathrm{R}_{\mathrm{w}, \mathrm{pl} \text {,pred, and plotted }}$ 
against the new relative slenderness $\bar{\lambda}$ obtained as the squared root of the predicted plastic resistance $R_{w, p l, p r e d}$ to predicted critical resistance $R_{w, c r, p r e d}$ ratio as given in Eq. (15). The new relationship is shown in Figs 15 and 16 for IOF and EOF loading, respectively, where it is observed that the replacement has not significantly affected the results in comparison with those obtained in Figs 8 and 9; hence, reflecting the suitability of the proposed predictive models for the elastic critical strength $R_{w, c r, p r e d}$ and the first order plastic resistance $\mathrm{R}_{\mathrm{w}, \mathrm{pl} \text {,pred. }}$

Finally, following the general expression for a strength curve given in Eq. (14), new coefficients $\mathrm{A}$ and $\mathrm{B}$ were derived for the design approach combining regression analyses and statistical evaluations in accordance with Annex D of EN 1990 [18] thereby obtaining the optimal values given in Eq. (22). The strength curves are shown in Figs 15 and 16 for IOF and EOF loading, respectively, together with those proposed by Duarte and Silvestre [23] for cold-formed carbon steel unstiffened C-sections and given in EN 1993-1-5 [25] for carbon steel plate girders (I-sections) subjected to patch loading.

$\chi= \begin{cases}\frac{0.29}{\bar{\lambda}^{0.82}} & \text { For IOF loading } \\ \frac{0.32}{\bar{\lambda}^{0.82}} & \text { For EOF loading }\end{cases}$

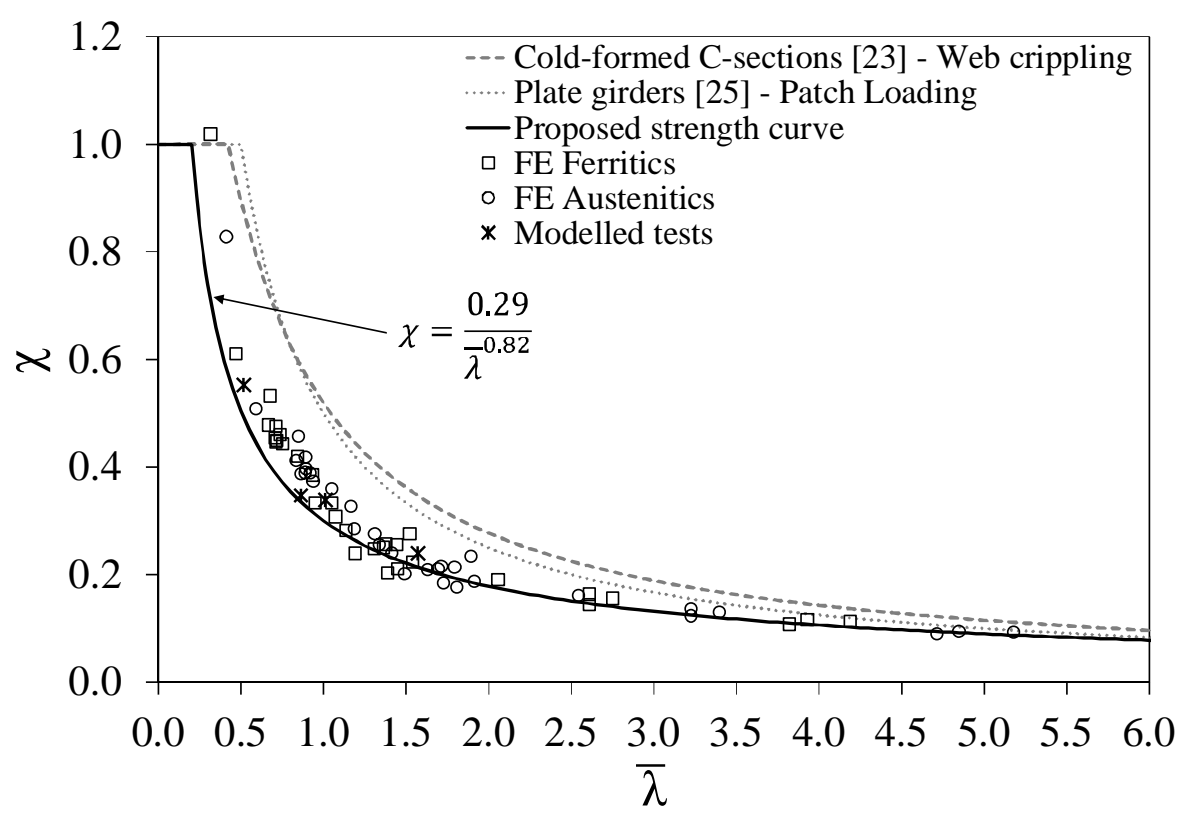

Fig. 15. Proposed Strength curve for IOF loading 


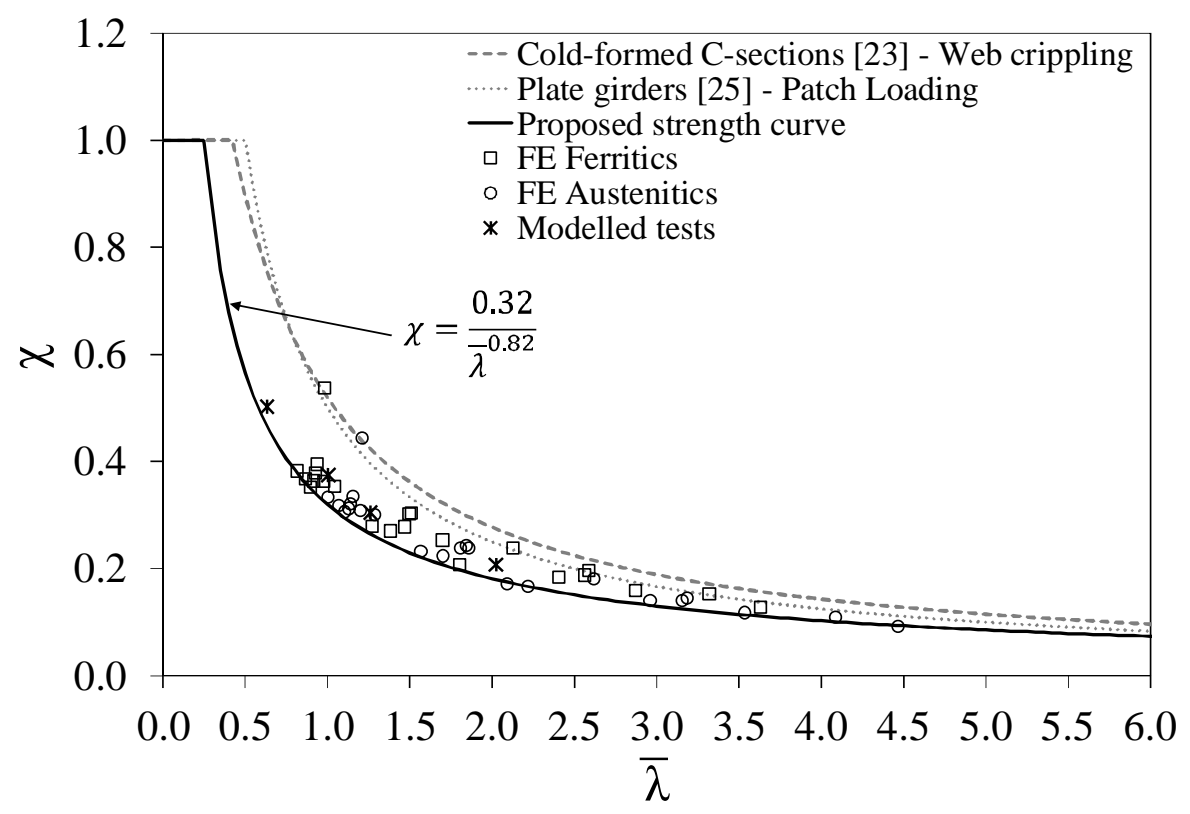

Fig. 16. Proposed Strength curve for EOF loading

For the statistical evaluation of the proposed design approach (resistance model), the database was split into two sub-sets based on their material grade to consider the difference in over-strength ratio (measured/minimum specified strength) following recommendations of [33]. Details of the procedure to statistically validate a resistance model are given in [34]. A summary of key statistical parameters is presented in Table 8 where $\mathrm{n}$ is the population of the data under consideration, $\mathrm{b}$ is the mean value of numerical data to predicted resistance ratio, $V_{\delta}$ is coefficient of variation of the numerical data relative to the resistance model (error of the model) and $\mathrm{V}_{\mathrm{r}}$ is combined coefficient of variation making allowance for the error of the model $\mathrm{V}_{\delta}$, including the basic variables $\mathrm{V}_{\mathrm{xi}}$ and the FE model $\mathrm{V}_{\mathrm{FEM}}$ [35]. The adopted coefficients of variation for the basic variables were [33]: 0.05 for the coefficient of variation of geometric properties; 0.066 and 0.050 for the coefficient of variation associated with the material strength for austenitic and ferritic stainless steel, respectively; material over-strength of 1.3 for austenitic stainless steel and 1.2 for ferritic stainless steel. The results of the statistical evaluation show that the proposed design approach is reliable $\left(\gamma_{\mathrm{M} 1} \leq 1.1\right.$ for safe design) for a partial safety factor of $\gamma_{\mathrm{M} 1}=1.1$.

Table 8. Statistical results and partial safety factor for the proposed strength curves

\begin{tabular}{cccccccc}
\hline Loading & Material & $\mathrm{n}$ & $\mathrm{b}$ & $\mathrm{V}_{\delta}$ & $\mathrm{V}_{\mathrm{FEM}}$ & $\mathrm{V}_{\mathrm{r}}$ & $\gamma_{M 1}$ \\
\hline \multirow{2}{*}{ IOF } & Ferritics & 32 & 1.113 & 0.088 & 0.020 & 0.115 & 1.078 \\
& Austenitics & 32 & 1.129 & 0.088 & 0.020 & 0.122 & 1.075 \\
\hline \multirow{2}{*}{ EOF } & Ferritics & 23 & 1.149 & 0.120 & 0.096 & 0.169 & 0.977 \\
& Austenitics & 23 & 1.139 & 0.109 & 0.096 & 0.174 & 1.013 \\
\hline
\end{tabular}

\subsection{Comparison with numerical data and design models}

The obtained numerical ultimate resistances per web of the generated models in the parametric study $\mathrm{R}_{\mathrm{w}, \mathrm{u}, \mathrm{num}}$ are compared herein with predicted resistances using $\mathrm{EN}$

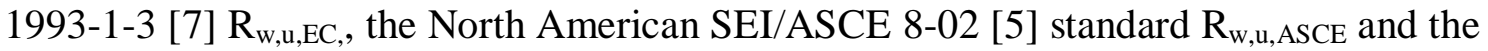
proposed design approach based on strength curves $R_{\mathrm{w}, \mathrm{u}, \chi-\lambda}$ given in Eqs. (15-22). The partial safety factor was set to unity to allow direct comparison between resistances which are shown in Figs 17 and 18 for IOF and EOF loading, respectively. In these figures, the numerical resistances are normalized by the respective predictive methods 
and plotted against the slenderness parameter $\bar{\lambda}$ determined in accordance with Eq. (15) using predictive models derived in Eqs. (17-21). Table 9 presents such comparison in terms of mean numerical-to-predicted ratio and coefficient of variation (COV). The results show that both EN 1993-1-3 [7] and the North American SEI/ASCE 8-02 [5] standard provide similar results yielding conservative predictions and large scatter whereas the proposed design approach based on strength curves $\chi(\bar{\lambda})$ offer the most accurate predictions. Note that the accuracy of the proposed method remains constant with increasing relative slenderness $\bar{\lambda}$ leading to a significant reduction in scatter.

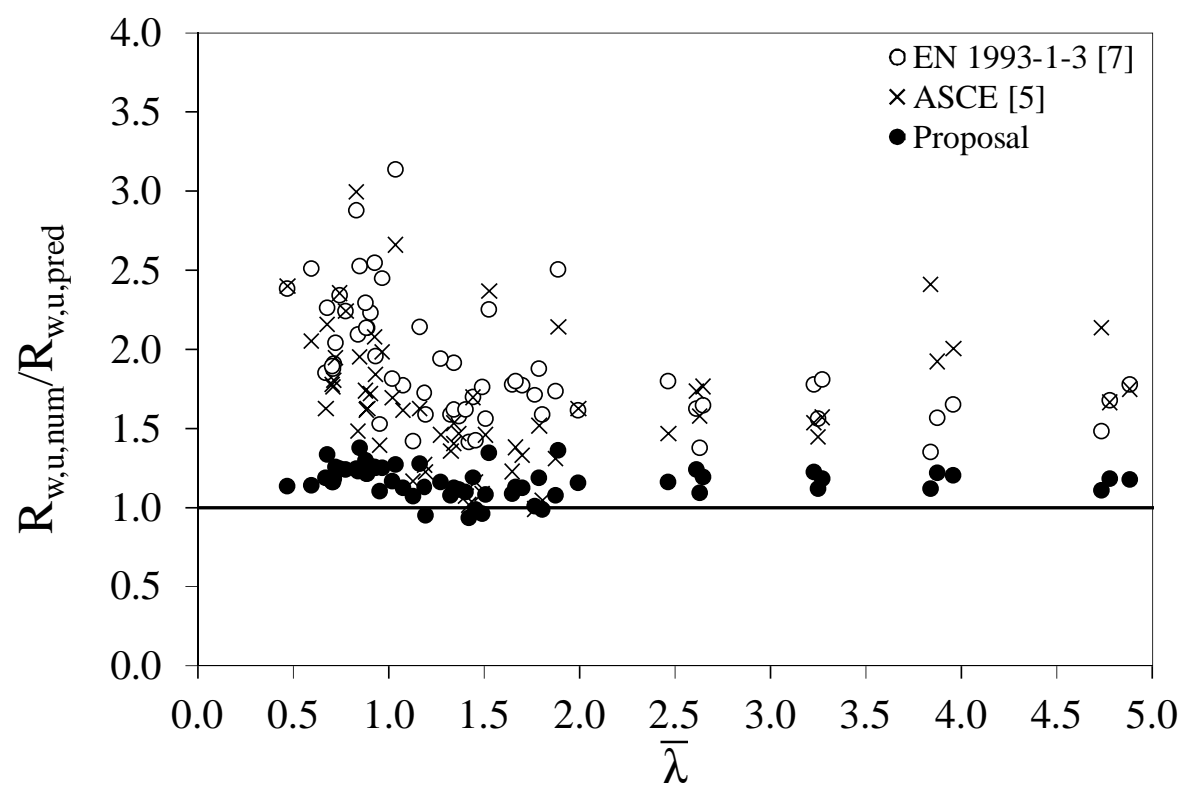

Fig. 17. Comparison of numerical web crippling strength with proposed design method and design standards for IOF loading

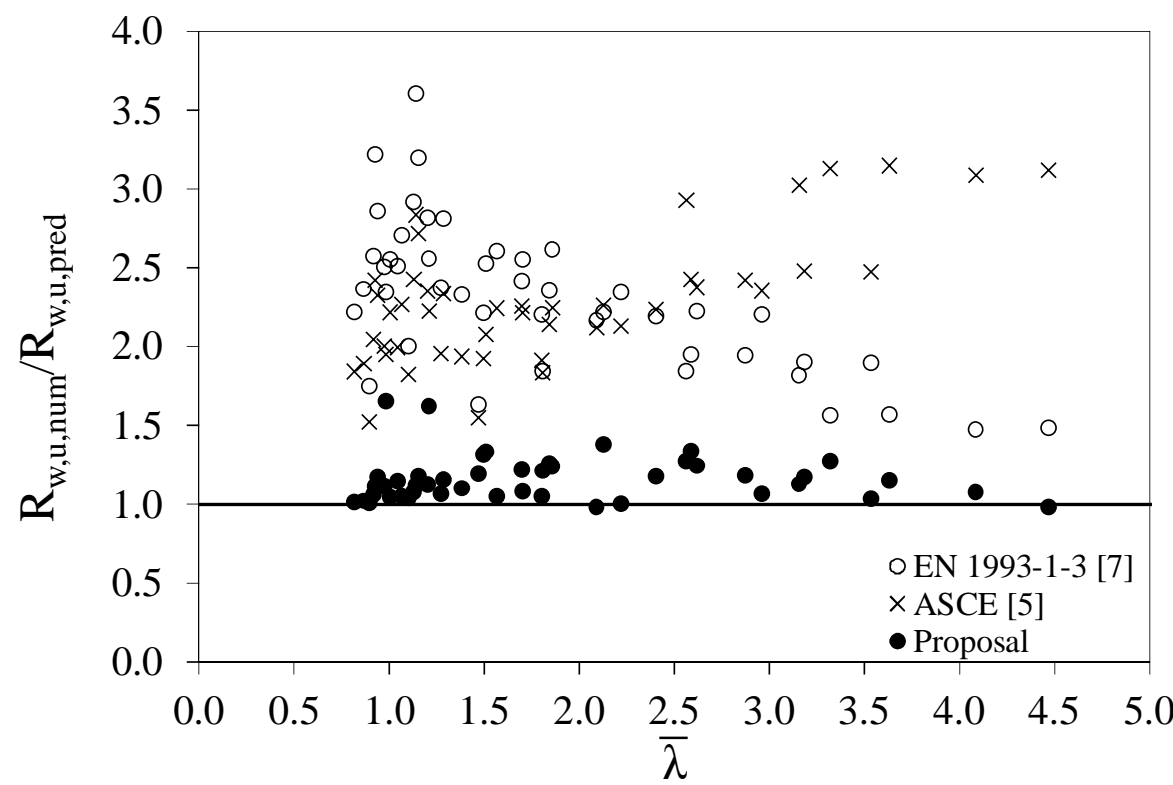

Fig. 18. Comparison of numerical web crippling strength with proposed design method and design standards for EOF loading 
Table 9. Comparison of ultimate web crippling capacity against different formulations for generated models in the parametric study

\begin{tabular}{|c|c|c|c|c|}
\hline Load case & Data source & Ratio & Mean & $\mathrm{COV}$ \\
\hline \multirow{6}{*}{ IOF } & \multirow{3}{*}{$\mathrm{FE}$} & $\mathrm{R}_{\mathrm{w}, \mathrm{u}, \mathrm{num}} / \mathrm{R}_{\mathrm{w}, \mathrm{u}, \mathrm{EC}}$ & 1.931 & 0.217 \\
\hline & & $\mathrm{R}_{\mathrm{w}, \mathrm{u}, \text { num }} / \mathrm{R}_{\mathrm{w}, \mathrm{u}, \mathrm{ASCE}}$ & 1.719 & 0.262 \\
\hline & & $\mathrm{R}_{\mathrm{w}, \mathrm{u}, \mathrm{num}} / \mathrm{R}_{\mathrm{w}, \mathrm{u}, \chi-\lambda}$ & 1.172 & 0.086 \\
\hline & \multirow{3}{*}{ Tests $[17,36]$} & $\mathrm{R}_{\mathrm{w}, \mathrm{u}, \text { test }} / \mathrm{R}_{\mathrm{w}, \mathrm{u}, \mathrm{EC}}$ & 1.709 & 0.050 \\
\hline & & $\mathrm{R}_{\mathrm{w}, \mathrm{u}, \text { test }} / \mathrm{R}_{\mathrm{w}, \mathrm{u}, \mathrm{ASCE}}$ & 1.603 & 0.064 \\
\hline & & $\mathrm{R}_{\mathrm{w}, \mathrm{u}, \text { test }} / \mathrm{R}_{\mathrm{w}, \mathrm{u}, \chi-\lambda}$ & 1.117 & 0.056 \\
\hline \multirow{6}{*}{ EOF } & \multirow{3}{*}{ FE } & $\mathrm{R}_{\mathrm{w}, \mathrm{u}, \mathrm{num}} / \mathrm{R}_{\mathrm{w}, \mathrm{u}, \mathrm{EC}}$ & 2.303 & 0.202 \\
\hline & & $\mathrm{R}_{\mathrm{w}, \mathrm{u}, \text { num }} / \mathrm{R}_{\mathrm{w}, \mathrm{u}, \mathrm{ASCE}}$ & 2.286 & 0.174 \\
\hline & & $\mathrm{R}_{\mathrm{w}, \mathrm{u}, \mathrm{num}} / \mathrm{R}_{\mathrm{w}, \mathrm{u}, \boldsymbol{\gamma}-\lambda}$ & 1.158 & 0.123 \\
\hline & \multirow{3}{*}{ Tests [17] } & $\mathrm{R}_{\mathrm{w}, \mathrm{u}, \text { test }} / \mathrm{R}_{\mathrm{w}, \mathrm{u}, \mathrm{EC}}$ & 2.572 & 0.027 \\
\hline & & $\mathrm{R}_{\mathrm{w}, \mathrm{u}, \text { test }} / \mathrm{R}_{\mathrm{w}, \mathrm{u}, \mathrm{ASCE}}$ & 2.073 & 0.110 \\
\hline & & $\mathrm{R}_{\mathrm{w}, \mathrm{u}, \text { test }} / \mathrm{R}_{\mathrm{w}, \mathrm{u}, \boldsymbol{\gamma}-\lambda}$ & 1.160 & 0.037 \\
\hline
\end{tabular}

\section{Validation of the design approach with test data}

The proposed design approach is validated in this section on the basis of available test data, including austenitic hat sections under IOF loading [36] and ferritic hat sections under both IOF and EOF loading [17]. As commented before, all relevant published test data on stainless steel are summarized in Table 2 . The mean values and coefficients of variation of the test results $R_{\mathrm{w}, \mathrm{u} \text {,test }}$ normalized by predicted ultimate resistances using the three considered approaches: EN 1993-1-3 [7] $R_{\mathrm{w}, \mathrm{u}, \mathrm{EC}}$; the North American SEI/ASCE 8-02 [5] standard $\mathrm{R}_{\mathrm{w}, \mathrm{u}, \mathrm{ASCE}}$; and the proposed design approach based on strength curves $R_{w, u, x-\lambda}$ given in Eqs. (15-22), are shown in Table 9, whereas comparisons of the predictions with existing tests are given in Table 10. Similarly to the comparison based on numerical results, the proposed design approach for web crippling design based on strength curves controlled by slenderness-based functions $\chi(\bar{\lambda})$ achieve a significant reduction in terms of mean and scatter. Figs 19 and 20 reflect the accuracy of the proposed design approach for IOF and EOF loading, respectively, where it is also observed that all predicted resistances are safe.

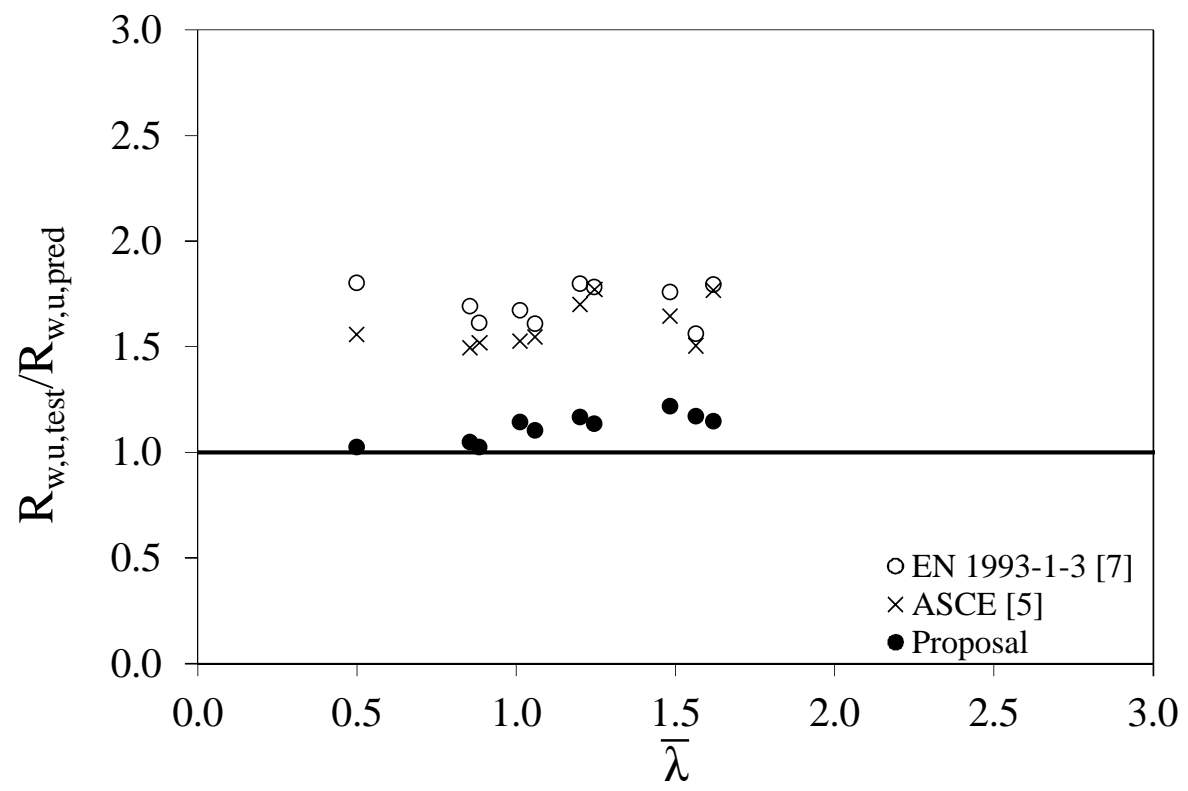

Fig. 19. Comparison of test web crippling strength with proposed design method and design standards for IOF loading 


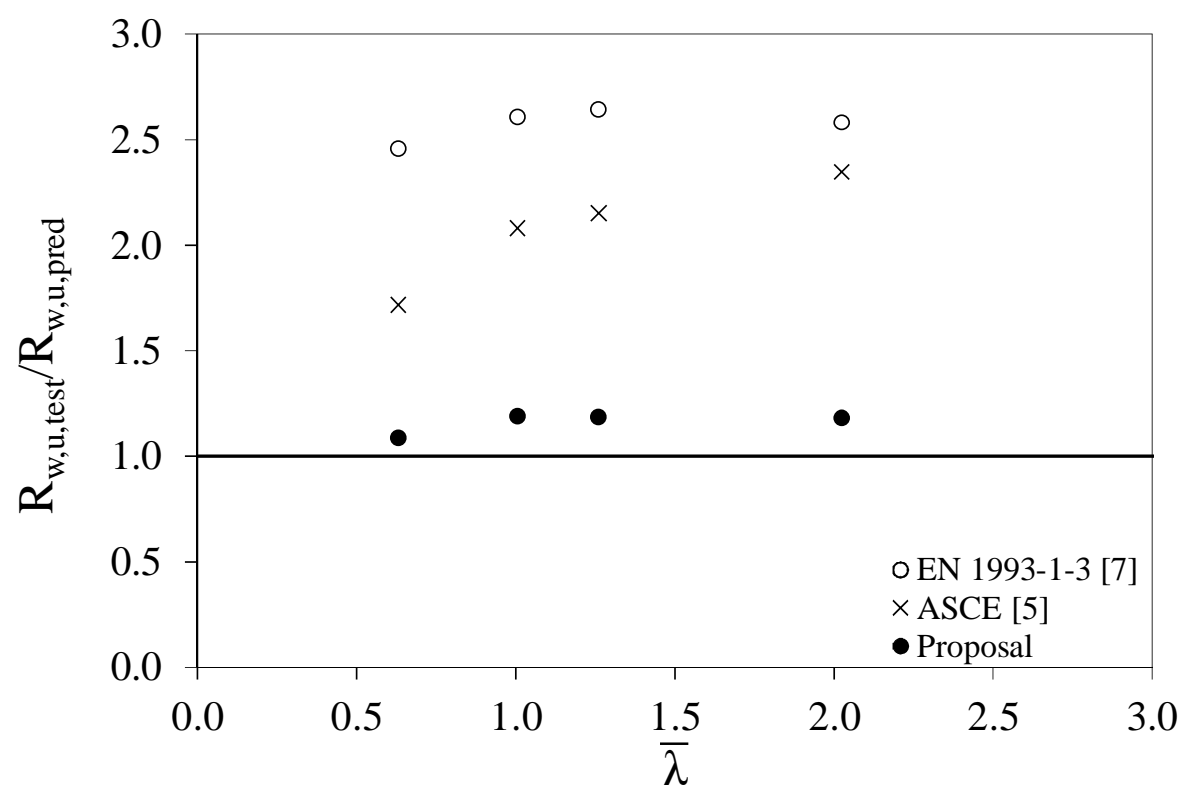

Fig. 20. Comparison of test web crippling strength with proposed design method and design standards for EOF loading

Table 10. Comparison of ultimate web crippling capacity against different formulations for collected tests

\begin{tabular}{|c|c|c|c|c|c|c|c|c|}
\hline Beam & $\begin{array}{c}\text { Source, } \\
\text { Load type }\end{array}$ & $\begin{array}{c}\mathrm{R}_{\mathrm{w}, \mathrm{u}, \text { test }} \\
(\mathrm{kN})\end{array}$ & $\begin{array}{c}\mathrm{R}_{\mathrm{w}, \mathrm{u}, \mathrm{EC}} \\
(\mathrm{kN})\end{array}$ & $\begin{array}{c}\mathrm{R}_{\mathrm{w}, \mathrm{u}, \mathrm{ASCE}} \\
(\mathrm{kN})\end{array}$ & $\begin{array}{l}\mathrm{R}_{\mathrm{w}, \mathrm{u}, \boldsymbol{\gamma},-\lambda} \\
\mathrm{kN})\end{array}$ & $\begin{array}{l}\mathrm{R}_{\mathrm{w}, \mathrm{u}, \mathrm{test}} / \\
\mathrm{R}_{\mathrm{w}, \mathrm{u}, \mathrm{EC}} \\
\end{array}$ & $\begin{array}{l}\mathrm{R}_{\mathrm{w}, \mathrm{u}, \mathrm{tess}} \mathrm{t} \\
\mathrm{R}_{\mathrm{w}, \mathrm{u}, \mathrm{ASCE}}\end{array}$ & $\begin{array}{l}R_{w, u, \text { test }} / \\
R_{w, u, \gamma-\lambda}\end{array}$ \\
\hline ITH_10 & [17] IOF & 5.00 & 3.20 & 3.32 & 4.28 & 1.562 & 1.504 & 1.169 \\
\hline ITH_15 & [17] IOF & 10.37 & 6.19 & 6.80 & 9.08 & 1.674 & 1.525 & 1.142 \\
\hline ITH_20 & [17] IOF & 17.42 & 10.29 & 11.65 & 16.64 & 1.693 & 1.496 & 1.047 \\
\hline ITH_30 & [17] IOF & 27.51 & 15.27 & 17.65 & 26.84 & 1.802 & 1.558 & 1.025 \\
\hline $\mathrm{H} 100-100 \times 2-C 700$ & [36] IOF & 24.75 & 15.35 & 16.30 & 24.19 & 1.613 & 1.519 & 1.023 \\
\hline H150-100x2-C700 & [36] IOF & 25.01 & 15.53 & 16.18 & 22.64 & 1.610 & 1.546 & 1.104 \\
\hline H100-100x2-C850 & [36] IOF & 31.20 & 17.34 & 18.36 & 26.77 & 1.800 & 1.700 & 1.165 \\
\hline H150-100x2-C850 & [36] IOF & 31.02 & 17.62 & 18.87 & 25.51 & 1.760 & 1.644 & 1.216 \\
\hline $\mathrm{H} 100-100 \times 2-\mathrm{C} 850$ & [36] IOF & 44.34 & 24.88 & 25.01 & 39.08 & 1.782 & 1.772 & 1.134 \\
\hline H150-100x2-C 850 & [36] IOF & 45.67 & 25.47 & 25.87 & 39.87 & 1.793 & 1.765 & 1.146 \\
\hline ETH_10 & [17] EOF & 3.59 & 1.39 & 1.53 & 3.04 & 2.581 & 2.347 & 1.179 \\
\hline ETH_15 & [17] EOF & 7.52 & 2.85 & 3.50 & 6.34 & 2.643 & 2.151 & 1.186 \\
\hline ETH_20 & [17] EOF & 12.96 & 4.97 & 6.23 & 10.91 & 2.606 & 2.079 & 1.188 \\
\hline ETH_30 & [17] EOF & 21.04 & 8.56 & 12.26 & 19.37 & 2.458 & 1.716 & 1.086 \\
\hline
\end{tabular}

\section{CONCLUSIONS}

A new design approach based on strength curves $\chi(\bar{\lambda})$ controlled by slenderness-based equations has been presented in this paper for web crippling design of stainless steel hat sections subjected to IOF and EOF loading. To this end, 8 tests on ferritic stainless steel hat sections under both loading types were modelled to calibrate and validate a comprehensive FE model. Further parametric studies were conducted to extend the available database over a large range of hat section geometries and two types of stainless steels: austenitic and ferritic stainless steel. The parametric study, consisted of three different types of analyses performed on every single generated model to determine: the elastic critical resistances $R_{\mathrm{w}, \mathrm{cr}}$; the first order plastic resistances $\mathrm{R}_{\mathrm{w}, \mathrm{pl}}$; and the web crippling ultimate resistances $R_{\mathrm{w}, \mathrm{u}}$. Following analysis of the results and in order to provide practical design expressions for the proposed design method, predictive models were derived for the elastic critical resistance $R_{\mathrm{w}, \mathrm{cr}}$ and the plastic resistance $\mathrm{R}_{\mathrm{w}, \mathrm{pl}}$. Having incorporated these predictive models in the $\chi-\bar{\lambda}$ space, the strength curves 
for the design of stainless steel hat sections were therefore derived through a combined process of regression analyses and statistical validations. Different expressions were set out for IOF and EOF loading. Comparisons of generated numerical models with design rules show that the proposed design approach fairly improves mean and reduces scatter for both IOF and EOF loading configurations enabling a more accurate and efficient design.

It should be highlighted that the calibration of the proposed design method was based on numerical models. Despite test data on stainless steel hat sections were used to validate the proposed design approach, those tests are limited to a small range of geometries. Hence, building on the limited existing test data and the satisfactory results achieved by the proposed design method, a new line of experimental investigation on the web crippling behaviour of cold-formed stainless steel cross-sections is essential to (1) enable a further validation of the derived strength curves for application to hat sections and (2) extend the methodology of strength design curves to cover the common structural section types and load cases.

\section{ACKNOWLEDGEMENTS}

The research leading to these results has received funding from the European Community's Research Fund for Coal and Steel (RFCS) under Grant Agreement No. RFSR-CT-2010-00026, Structural Applications for Ferritic Stainless Steels and from Ministerio de Ciencia e Innovación to the Project BIA 2012-36373. The first author is grateful to the Secretaria d'Universitats i de Recerca del Departament d'Economia i Coneixement de la Generalitat de Catalunya for their financial contribution. The authors gratefully acknowledge all the experimental information provided by Asko Talja and Petr Hradil from VTT Technical Research Centre of Finland. They would also like to thank Professor Feng Zhou from Tongji University for the provided support in the FE model.

\section{REFERENCES}

[1] Winter G, Pian RHJ. Crushing strength of thin steel webs. Engineering experiment station, Bulletin no. 35, Part 1. New York, USA; 1946.

[2] Winter G. 65th and 66th Progress reports on light gage steel beams of cold-formed steel. New York, USA; 1952 and 1953, respectively. Unpublished.

[3] AISI 1968 Edition. Specification for the design of cold-formed steel structural members. AISI (1968). Washington, DC: American Iron and Steel Institute; 1986.

[4] ASCE. Specification for the design of cold-formed stainless steel structural members. ANSI/ASCE 8-90. Reston, VA: American Society of Civil Engineers; 1991.

[5] ASCE. Specification for the design of cold-formed stainless steel structural members. SEI/ASCE 8-02. Reston, VA: American Society of Civil Engineers; 2002.

[6] EN 1993-1-4. Eurocode 3: Design of steel structures - Part 1-4: General rules Supplementary rules for stainless steels. Brussels: European Committee for Standardization (CEN); 2006. 
[7] EN 1993-1-3. Eurocode 3: Design of steel structures - Part 1-3: General rules Supplementary rules for cold-formed members and sheeting. Brussels: European Committee for Standardization (CEN); 2006.

[8] Yu WW, LaBoube RA. Cold-Formed Steel Design. 4th ed. New York: John Wiley \& Sons Inc; 2010.

[9] Bakker MCM, Stark JWB. Theoretical and experimental research on web crippling of cold-formed flexural steel members. Thin-Walled Structures 1994;18:261-90.

[10] Hofmeyer H, Kerstens JGM, Snijder HH, Bakker MCM. New prediction model for failure of steel sheeting subject to concentrated load (web crippling) and bending. ThinWalled Structures 2001;39:773-96.

[11] Korvink SA, van den Berg GJ, van der Merwe P. Web crippling of stainless steel cold-formed beams. Journal of Constructional Steel Research 1995;34:225-48.

[12] Talja A, Salmi P. Design of stainless steel RHS beams, columns and beamcolumns. VTT Research Notes 1619. Findland: VTT Technical Research Centre of Finland; 1995.

[13] Zhou F, Young B. Cold-formed stainless steel sections subjected to web crippling. Journal of Structural Engineering (ASCE) 2006;132:134-44.

[14] Zhou F, Young B. Cold-formed high-strength stainless steel tubular sections subjected to web crippling. Journal of Structural Engineering (ASCE) 2007;133:368-77.

[15] Zhou F, Young B. Experimental and numerical investigations of cold-formed stainless steel tubular sections subjected to concentrated bearing load. Journal of Constructional Steel Research 2007;63:1452-66.

[16] Bock M, Arrayago I, Real E, Mirambell E. Study of web crippling in ferritic stainless steel cold-formed sections. Thin-Walled Structures 2013;69:29-44.

[17] Talja A, Hradil P. Work package 2: Model calibration tests - Test Report. Report to the RFCS Project - Structural applications of ferritic stainless steel (SAFSS). Contract no. RFSR-CT-2010-00026. Finland: VTT Technical Research Centre of Finland; 2011.

[18] EN 1990. Eurocode-basis of structural design. Brussels: European Committee for Standardization (CEN); 2002.

[19] Mirambell E, Real E. On the calculation of deflections in structural stainless steel beams: an experimental and numerical investigation. Journal of Construction Steel Research 2000;54:109-33.

[20] Rasmussen KJR. Full-range stress-strain curves for stainless steel alloys. Journal of Construction Steel Research 2003;59:47-61. 
[21] Hofmeyer H. Combined web crippling and bending moment failure of firstgeneration trapezoidal steel sheeting [dissertation]. The Netherlands: Eindhoven University of Technology; 2000.

[22] Kaitila O. Web crippling of cold-formed thin-walled steel cassettes [dissertation]. Finland: Helsinki University of Technology; 2004.

[23] Duarte APC, Silvestre N. A new slenderness-based approach for the web crippling design of plain channel steel beams. International Journal of Steel Structures 2013;3:421-34.

[24] Bock M, Real E, Mirambell E. Strength curves for web crippling design: First approach for stainless steel hat sections based on numerical analyses. Proceedings of the 7th European conference on steel and composite structures (Eurosteel 2014); 2014 Sep 10-12; Naples, Italy. p. 41-2.

[25] EN 1993-1-5. Eurocode 3: Design of steel structures - Part 1-5: General rules Plated structural elements. Brussels: European Committee for Standardization (CEN); 2006.

[26] Johansson B, Lagerqvist O. Resistance of plate edges to concentrated forces. Journal of Constructional Steel Research 1995;32:69-105.

[27] Lagerqvist O, Johansson B. Resistance of I-girders to concentrated loads. Journal of Constructional Steel Research 1996;39:87-119.

[28] Young B, Hancock GJ. Design of cold-formed channels subjected to web crippling. Journal of Structural Engineering (ASCE) 2001;127:1137-44.

[29] Zhao XL, Hancock GJ. Square and rectangular hollow sections subjected to combined actions. Journal of Structural Engineering (ASCE) 1992;118:648-68.

[30] Zhao XL, Hancock GJ. Square and rectangular hollow sections under transverse end-bearing force. Journal of Structural Engineering (ASCE) 1995;121:1323-9.

[31] Zhou F, Young B. Yield line mechanism analysis on web crippling of cold-formed stainless steel tubular sections under two-flange loading. Engineering Structures 2006;28:880-92.

[32] Roberts TM, Rockey KC. A mechanism solution for predicting the collapse loads of slender plate girders when subjected to in-plane patch loading. Proceedings of the Institution of Civil Engineers 1979;67:155-75.

[33] Baddoo N, Francis P. Re-evaluation of EN 1993-1-4 partial resistance factors for stainless steel. The Steel Construction Institute; 2013.

[34] Bock M, Mirada FX, Real E. Statistical evaluation of a new resistance model for cold-formed stainless steel cross-sections subjected to web crippling. International Journal of steel structures 2015;1:227-244. 
[35] Davaine L. Formulations de la résistance au lancement d'une âme métallique de pont raidie longitudinalement - Résistance dite de "Patch Loading" [dissertation].

France: L’Institut National des Sciences Appliquées de Rennes; 2005. French.

[36] Talja A. Work packages 2 and 3: Test results of RHS, top hat and sheeting profiles. Report to the RFCS Project - Structural design of austenitic cold-worked stainless steel. Contract no. 7210 PR/ 318. Finland: VTT Technical Research Centre of Finland; 2003.

[37] Baehre R. Sheet metal panels for use in building construction-Recent research projects in Sweden. Proceedings of the 3rd International specialty conference on coldformed steel structures; 1975; Missouri, USA; 1975. p. 383-455.

[38] Hetrakul N, Yu WW. Structural behavior of beam webs subjected to web crippling and a combination of web crippling and bending. Final Report, Civil Engineering Study 78-4. Missouri, USA; 1978.

[39] Yu WW. Web crippling and combined web crippling and bending of steel decks. Structural Series, Civil Engineering Study 81-2. Missouri, USA; 1981.

[40] Wing BA. Web crippling and the interaction of bending and web crippling of unreinforced multi-web cold-formed steel sections [M.Sc Project]. Canada: University of Waterloo; 1981.

[41] Studnicka J. Web crippling of wide deck sections. $10 \mathrm{t}^{\mathrm{h}}$ International specialty conference on cold-formed steel structures. Missouri, USA; 1990. p. 317-34.

[42] CSA Group. Cold-formed steel structural members. CSA S136-84. Ontario: Canadian Standards Association Group; 1984.

[43] AISI 1986 Edition. Specification for the design of cold-formed steel structural members. AISI (1986). Washington, DC: American Iron and Steel Institute; 1986.

[44] Bhakta BH, LaBoube RA, Yu WW. The effect of flange restraint on web crippling strength. Final Report, Civil Engineering Study 92-1. Missouri, USA; 1992.

[45] Prabhakaran K. Web crippling of cold-formed steel sections [Project Report]. Canada: University of Waterloo; 1993.

[46] CSA Group. Cold-formed steel structural members. CSA S136-94. Toronto: Canadian Standards Association Group; 1994.

[47] NAS. North American specification for the design of cold-formed steel structural members. NASPEC-2001. Washington, DC: American Iron and Steel Institute; 2001.

[48] Langan JE, LaBoube RA, Yu WW. Structural behavior of perforated web elements of cold-formed steel flexural members subjected to web crippling and a combination of web crippling and bending. Final Report, Civil Engineering Study 94-3. Missouri, USA; 1994. 
[49] Cain DE, LaBoube RA, Yu WW. The effect of flange restraint on web crippling strength of cold formed steel Z-and I-Sections. Final Report, Civil Engineering Study 95-3. Missouri, USA; 1995.

[50] Gerges RR. Web crippling of single web cold-formed steel members subjected to End One-Flange loading [MSc Project]. Canada: University of Waterloo; 1997.

[51] Wu S, Yu WW, LaBoube RA. Strength of flexural members using structural grade 80 of A653 Steel (web crippling tests). $3^{\text {rd }}$ Progress Report, Civil Engineering Study 973. Missouri, USA; 1997.

[52] Young B, Hancock GJ. Web crippling behavior of cold-formed unlipped channels. Proceedings of the 14th International specialty conference on cold-formed steel structures; 1998 October; Missouri, USA; 1998.

[53] AISI 1996 Edition. Specification for the design of cold-formed steel structural members. AISI (1996). Washington, DC: American Iron and Steel Institute; 1996.

[54] Beshara B, Schuster M. Web crippling data and calibrations of cold-formed steel members. AISI Research Report RP00-2. Washington, DC; 2000.

[55] AISI 2002 Edition. Specification for the design of cold-formed steel structural members. AISI (2002). Washington, DC: American Iron and Steel Institute; 2002.

[56] Korvink SA, van den Berg GJ. Web crippling of stainless steel cold-formed beams. Proceedings of the 12th International specialty conference on cold-formed steel structures; 1994. Missouri, USA. p. 551-69.

[57] Talja A. Work package 3: Test report on sheetings. Report to the ECSC Project Development of the use of stainless steel in construction. Contract no. $7210 \mathrm{SA} / 842$. Finland: VTT Technical Research Centre of Finland; 1997.

[58] Sélen E. Work package 3: Web crippling. Report to the ECSC Project Development of the use of stainless steel in construction. Contract no. 7210 SA/ 842. Sweden: Luleå Institute of Technology; 2000.

[59] Zilli G. Work package 3: Test results on unstiffened profiles. Report to the RFCS Project - Structural design of austenitic cold-worked stainless steel. Contract no. 7210 PR/ 318. Italy: Centro Sviluppo Materiali; 2003.

[60] Zhou F and Young B. Experimental investigation of cold-formed high-strength stainless steel tubular members subjected to combined bending and web crippling. Journal of Structural Engineering (ASCE) 2007;133:1027-34.

[61] Gardner L, Talja A, Baddoo NR. Structural design of high-strength austenitic stainless. Thin-Walled Structures 2006;44:517-28.

[62] Real E, Arrayago I, Mirambell E, Marimon F, Ferrer M. Work package 3: Decking tests in the construction stage. Report to the RFCS Project - Structural applications of ferritic stainless steel (SAFSS). Contract no. RFSR-CT-2010-00026. Spain: Universitat Politècnica de Catalunya (UPC); 2013. 